\title{
Robot-City Interaction: Mapping the Research Landscape-A Survey of the Interactions Between Robots and Modern Cities
}

\author{
Ilaria Tiddi ${ }^{1}$ (D) Emanuele Bastianelli ${ }^{2} \cdot$ Enrico Daga $^{3} \cdot$ Mathieu d'Aquin $^{4} \cdot$ Enrico Motta $^{3}$
}

Accepted: 15 February 2019 / Published online: 14 March 2019

(c) The Author(s) 2019

\begin{abstract}
The goal of this work is to describe how robots interact with complex city environments, and to identify the main characteristics of an emerging field that we call Robot-City Interaction (RCI). Given the central role recently gained by modern cities as use cases for the deployment of advanced technologies, and the advancements achieved in the robotics field in recent years, we assume that there is an increasing interest both in integrating robots in urban ecosystems, and in studying how they can interact and benefit from each others. Therefore, our challenge becomes to verify the emergence of such area, to assess its current state and to identify the main characteristics, core themes and research challenges associated with it. This is achieved by reviewing a preliminary body of work contributing to this area, which we classify and analyze according to an analytical framework including a set of key dimensions for the area of RCI. Such review not only serves as a preliminary state-of-the-art in the area, but also allows us to identify the main characteristics of RCI and its research landscape.
\end{abstract}

Keywords Robots · City ecosystems · Robot-City interaction $\cdot$ Smart cities

\section{Introduction}

Modern cities have become a key element of the strategies for future investments not only for the important role they play in the socio-economic growth worldwide, but also for

Ilaria Tiddi

i.tiddi@vu.nl

Emanuele Bastianelli

e.bastianelli@hw.ac.uk

Enrico Daga

enrico.daga@open.ac.uk

Mathieu d'Aquin

mathieu.daquin@insight-centre.org

Enrico Motta

enrico.motta@open.ac.uk

1 Faculty of Computer Science, Vrije Universiteit Amsterdam, De Boelelaan 1081-1089, 1081 HV Amsterdam, The Netherlands

2 School of Mathematical and Computer Sciences, Currie, Edinburgh EH14 4A, UK

3 Knowledge Media Institute, The Open University, Walton Hall, Milton Keynes MK7 6AA, UK

4 Insight Centre for Data Analytics, The DERI Building, IDA Business Park, Lower Dangan, Galway, Ireland the increasing difficulty in being environmentally sustainable $[31,71]$. As a consequence, a considerable number of efforts have been put by both the academic and industrial research communities into exploiting techniques from a wide range of domains such as ubiquitous computing, data analysis and knowledge engineering, with the aim of enabling cities to be more efficient, productive and competitive [4,9,24,52,54].

Robotics has also reached increased maturity in the last decades, as demonstrated by the amount of efficient open source hardware and software components, the availability of reliable techniques for basic perception, manipulation and navigation tasks, as well as the increasing number of cost-accessible robotic platforms [82]. Thanks to these advancements, robots and autonomous systems have been identified as one of the most important modern disruptive technologies [66], i.e. technologies enabling massive economic transformations in the near future, and policy makers worldwide are nowadays investing to support the development of urban infrastructures able to integrate robotic technologies, therefore allowing such transformations [97].

As a consequence, national and local governments have started experimenting the integration of robots in urban spaces in the last years, with the goal of showing how such urban transformations facilitate the citizens' everyday life and demonstrate good city governance. If we take the exam- 


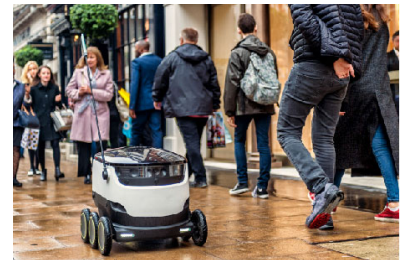

(a) Starship robots delivering groceries in the centre of Milton Keynes.

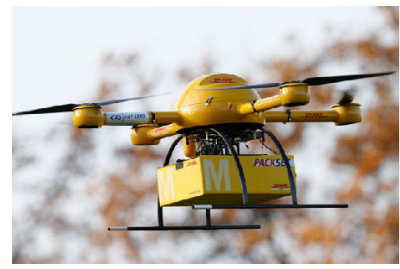

(b) Drones services for the Flying High Challenge.
Fig. 1 Civic and commercial uses of robots in UK cities

ple of the UK, several initiatives have been launched to support cities willing to develop robot and infrastructures to transform their services, e.g. the Starship delivery services ${ }^{1}$ or the Nesta Flying Challenge ${ }^{2}$ (cfr. Fig. 1). Other examples include cities deploying autonomous cars to enhance urban mobility, ${ }^{3}$ drone deliveries employed for commercial or first-aid emergency scenarios, ${ }^{4}$ and social robots operating in public and commercial spaces in many guises (waiters, policemen, receptionists ${ }^{5}$ ).

Considering this, the main hypothesis of our work is that the study of how robots can integrate and co-operate with city environments is emerging as a new area of research, which we call Robot-City Interaction (RCI). Our challenge therefore becomes to assess the current state of this area, and to identify the main characteristics, the core themes and the research challenges associated with it. The methodology we use to achieve this consists in identifying a set of key dimensions for RCI and using them to review a body of relevant work, which can serve not only as a preliminary state-of-theart for further reference, but also to give a more complete view on what is RCI and which is its research landscape.

The contributions of our paper can therefore be summarized as follows:

- we design a thorough methodology to identify RCI as an area of research;

- we define a set of dimensions for analyzing works in the RCI area;

- we provide a review of the state of the art in RCI;

- we give a description of RCI and its main characteristics, for further reference;

- we present the key research challenges, main areas and research landscape in RCI.

\footnotetext{
1 https://www.starship.xyz.

2 http://flyinghighchallenge.org/.

3 https://avsincities.bloomberg.org/.

${ }^{4}$ https://www.bbc.co.uk/news/technology-44068637.

5 https://tinyurl.com/ycmehvgr.
}

In the remainder of the paper, we present the research methodology that was adopted (Sect. 2), followed by the analytical framework used to review the state-of-the-art (Sect. 3), which is then surveyed in Sect. 4. Section 5 summarizes our findings, draws the main characteristics and challenges of RCI, and describes its research landscape. Conclusions and general remarks are presented in Sect. 6.

\section{Research Methodology}

Based on the methodology for literature search described in [105], our survey consists in defining first the core terminology of our work, as well as the search and selection criteria to be used (rest of this section), then presenting the analytical framework (Sect. 3) through which the literature can be analyzed and synthethized (Sect. 4), and finally describing the area of Robot-City Interaction with its characteristics and its research landscape (Sect. 5).

\subsection{Core Terminology}

Here, the main terminology of our work (the terms city, robot and interaction) is explained based on the relevant literature.

Cities and modern cities We define a city as "a reasonably large and permanent concentration of people within a limited territory $[\ldots]$ concentrating commercial, administrative, industrial, cultural and other functions" [58]. In such territory, or urban space, three factors are essential:

- a large, culturally heterogeneous population, which is densely settled and bound in a municipality [36];

- the relationships held among the population, which change from being primary (familiar and neighborhoodrelated) contacts to being secondary/tertiary (impersonal, formal and bureaucratic contacts) [111];

- the facilities established by or for the population, i.e. "the fixed site, the durable shelter, the permanent facilities for assembly, interchange and storage; the essential social means are the social division of labor, which serves not merely the economic life but the cultural processes. $[\ldots]$ The city in its complete sense, then, is a geographic plexus, an economic organization, an institutional process, a theatre of social action, and an aesthetic symbol of collective unity." [73].

In this definition we also include the smart cities, a new urban innovation paradigm which has emerged in the last years driven by the motivation that technology advancement could enable solutions to make cities more efficient and sustainable. Smart cities are cities that use networked infrastructures to improve economic and political efficiency and enable social, cultural and urban development [43], in which the kind of 
technologies used, the scenarios in which they can be applied and the high diversity and distribution of data sources is the main novelty [21].

Autonomous robots A generic definition of robots is employed in our work, i.e. any active, artificial, physical agent whose environment is the physical world, which makes decisions on its own, guided by the feedback it gets from its sensing apparatuses [84]. We aim at investigating which robots could live in, engage with and benefit from a city ecosystem. In other words, we consider a robot as an agent with sensing capabilities, some levels of autonomy, and operating in a (surrounding) environment.

Interactions In general, interaction can be defined as "an occasion when two or more people or things communicate with or react to each other", ${ }^{6}$ therefore stressing the importance of a reciprocal effect between its participants. In computer science, this reciprocal effect is mostly represented as information flowing from an artefact to a user and vice versa, e.g. Human-Computer Interaction and HumanRobot Interaction ${ }^{7}$ [50]. Based on this, we define interaction as the reciprocal influence that robots and city systems have upon each other or, in other words, the set of communications, connections, actions that exist in scenarios where both robots and the city infrastructures are involved.

\subsection{Search and Selection Criteria}

First, the literature was searched according to dates, area and keyword criteria described in the following.

Apart from a few notable exceptions that were included in the analysis, there is little work related to robots operating in modern cities before the year 2000. Hence, the search was restricted to the time-span between 2000 and 2018.

We then explored areas that we considered could be treating one or more aspects of Robot-City Interaction. These can be roughly divided in three big (but not exclusive) areas, namely Robotics, Information Communication Technology and Computer Science. In the first area, we considered works on social robotics, cognitive robotics, aerial robotics, Human-Robot Interaction and Cloud Robotics. In the second area, we found works oriented towards problems of ubiquitous computing, sensors and sensor networks, internet of things, computer vision or ambient intelligence. In the last group, we considered work oriented to data management, artificial intelligence, data mining, machine learning, cognition and knowledge engineering.

We searched for papers combining words such as "robots/ autonomous systems/autonomous (mobile) agents" with words such as "city/cities", "smart city/smart cities", but

\footnotetext{
$\overline{6}$ http://dictionary.cambridge.org/dictionary/english/interaction.

7 See also Human-Machine Interaction and Animal-Computer Interaction.
}

also any sub-system of a city including, for instance, "road/crowd", "urban", "pedestrian/citizen", "water/pipes" etc.

Works were extracted both using Google Scholar and directly scanning journals and special issues (Intelligent Assistive Robots, International Journal of Robotic Research, International Journal of Social Robotics, Sensor Journal, to name a few) and conferences/workshops proceedings (e.g. robotics conferences as IROS, ICRA, AAMAS, RSS, HRI, and ubiquitous computing conferences as UBICOMP, ISC, SMARTGREENS) related to the areas described above. Both forward and backward search was used to look for further candidates, along with the scan of the bibliographies and related work of the already selected works. Using this methodology, we were guaranteed to analyze a sufficiently large spectrum of work to ground our study.

Finally, the relevance of the works with respect to RCI was assessed by four judges, i.e. a work was considered if at least two of the following conditions applied:

(1) Urban robots the work involves robots operating with some levels of autonomy in a urban space-a social space including a population involved in commercial, administrative, industrial or cultural activities (as per definition of Sect. 2.1);

(2) Smart infrastructures the work focuses on the technological integration of robots in a city ecosystem, and more particularly there is an aspect of data exchange between robots and the city infrastructures;

(3) Open-ended interactions the work studies robots operating in a highly-dynamic context involving interactions of different kinds, and where proactivity in decisionmaking is necessary to deal with an unforeseeable number of situations.

This guaranteed to clearly limit our selection to cases relevant to RCI, e.g. robots interacting with the crowds or operating in crowded environments, service robots in smart homes/hospitals/public spaces exchanging information with the city system, security/maintenance robots or driverless cars deployed by centralised infrastructures, while excluding hybrid cases such as intelligent environments, surgical robots, industrial manipulators and robot assisting elderly in their homes (unless an interaction with a city system was verified). Moreover, multiple references to the same project have been considered only if presenting a substantial difference, and discarded in the opposite case.

The final selection, available in Table 3 of Appendix at the end of this work, consists of 67 papers providing a preliminary state-of-the-art in the area of Robot-City Interaction. 
Table 1 Summary of the RCI analytical framework

\begin{tabular}{|l|c|c|c|c|c|c|}
\hline Robot type & Non-moving & Humanoid & \multicolumn{2}{c|}{ Wheeled } & Aerial & Marine \\
\hline Robot actions & Navigation & Perception & Management & Manipulation & Verbal Communication & Acquisition \\
\hline Level of autonomy & Low & \multicolumn{2}{c|}{ Medium } & \\
\hline \begin{tabular}{|l|l|l|l|c|} 
Urban context \\
City actuators
\end{tabular} & Land & Citizens & Government & \multicolumn{2}{c|}{ Technology } \\
\hline City domains & Living & Economy & Governance & Mobility & Environment & People \\
\hline
\end{tabular}

\begin{tabular}{|l|c|c|c|c|}
\hline \multicolumn{5}{|c|}{ Information context } \\
\hline Data volume & Megabytes & Gigabytes & Terabytes & Pentabytes \\
\hline Data velocity & Batch & Periodic & Near-time & Real-time \\
\hline Data variety & Unstructured & Semi-structured & Structured \\
\hline Data Openness & \multicolumn{2}{|c|}{ Restricted } & & Open \\
\hline
\end{tabular}

\begin{tabular}{|c|c|c|c|c|c|}
\hline \multicolumn{6}{|c|}{ Interaction context } \\
\hline Robot-Citizens & Intimate & Personal & Social & \multicolumn{2}{|c|}{ Public } \\
\hline Robot-Land & Exhibit & Passage & Special use & Secure & Backstage \\
\hline Robot-Government & \multicolumn{2}{|l|}{ Yes } & \multicolumn{3}{|c|}{ No } \\
\hline Robot-Data & Acquisition & \multicolumn{2}{|c|}{ Processing } & \multicolumn{2}{|c|}{ Dissemination } \\
\hline Robot-Robot & Heterogeneous team & \multicolumn{2}{|c|}{ Homogeneous team } & \multicolumn{2}{|c|}{ Single-robot team } \\
\hline
\end{tabular}

\section{The $\mathrm{RCl}$ Analytical Framework}

The analytical framework takes inspiration from semiotics theories aiming at studying how interactions are affected by the social and physical spaces in which they happen [92]. Main insights behind these approaches are the idea that studying an interaction involves more than the players that take part into it (e.g. the nature of the interaction itself or the scope of it), and that the physical space is a key element to interpret interactions. This presents an interesting overlap with the main concepts of RCI, as we have defined in Sect. 2.1.

Inspired by such theories, we identified the key aspects of works to be analysed (we call these dimensions) in light of established background literature, and then grouped them thematically according to four contexts. Such contexts, presented below, aim at describing not only the three players of RCI (the robots, the city as a complex ecosystem and the information they exchange), but also the nature of the interaction that is happening between them:

1. Agent context Dimensions describing characteristics specific to the autonomous agents acting in and with a city, e.g. the type of robots or their capabilities.

2. Urban context Dimensions characterizing the city as a set of connected infrastructures providing services to the citizens.

3. Information context Dimensions describing the information exchanged between the autonomous agents and the city, i.e. the nature of the communicated data.
4. Interaction context Dimensions characterizing the interactions between autonomous agents and single city systems, e.g. the citizens or the governance.

A summary of this framework is presented in Table 1.

\subsection{Agent Context}

As previously mentioned, the first analysis concerns aspects describing the autonomous agents that take part into in RCI scenarios. We consider here 3 dimensions: robot type, robot actions, level of autonomy.

Robot type This dimension aims at analyzing the type of robot that is employed in a Robot-City Interaction scenario. A reference work on the classification of robot types is [91], which categorizes robots as:

- ground, non-moving robots platforms with movable components such as the Baxter platforms; ${ }^{8}$

- ground, moving, human-like robots legged, humanoid or human-like robots such as Pepper, ${ }^{9}$ ASI-MO, ${ }^{10}$ or the Boston Dynamics suites; ${ }^{11}$

- ground, moving, wheeled robots robots provided with wheels, such as the Starship deliverers, the Robotnik

\footnotetext{
${ }^{8}$ https://www.baxter.com/inside-baxter/about/overview/corporate. page.

${ }^{9}$ https://www.ald.softbankrobotics.com/en/robots/pepper/.

${ }^{10} \mathrm{http}: / /$ asimo.honda.com/.

$11 \mathrm{http} / / / \mathrm{www}$. bostondynamics.com/index.html.
} 
Summit suites ${ }^{12}$ or Komodo, ${ }^{13}$ which are not necessarily human-like;

- aerial robots drones provided with rotors, such as the Erle Robotics's copters ${ }^{14}$ or the Parrot drones; ${ }^{15}$

- marine robots vessels used for underwater activities such as the Searobotics suite. ${ }^{16}$

Robot actions Here, we focus on which actions are mostly performed by robots in Robot-City Interaction scenarios. We consider high-level actions, re-adapted based on the work of [98]:

- navigation the fundamental act of moving from point $\mathrm{A}$ to point B;

- perception the act of perceiving and understanding the environment through sensing and interpreting sensory data;

- management the act of coordinating and managing the actions of humans and robots, acting independently or in groups;

- manipulation the act of interacting with the environment through body-part movements, hence including bodypart movement;

- verbal communication the act of interacting with the social world using the past experience, exhibiting social competencies;

- acquisition the act of interacting with the physical world acquiring new competencies. ${ }^{17}$

Levels of autonomy This dimension aims at analyzing which degree of autonomy the agents taking part to a Robot-City Interaction scenario exhibit. Defining autonomy represents a complex problem itself, and many taxonomies have been presented in the literature [6,35,93]. We chose therefore to adopt a simplified scale (from low to high) to describe the autonomy of the agents operating in RCI scenarios, and leave as future work the task of providing a more complete categorization. We invite the reader to refer to the cited works as further reference for the terminology. The scale ranges as follows:

- low autonomy includes the lowest levels of robot autonomy, e.g. manual, tele-operation and assisted teleoperation, in which the aspects of a task to achieve (e.g.

\footnotetext{
12 https://www.robotnik.eu/.

13 http://www.robotican.net/komodo.

14 http://erlerobotics.com/.

15 https://www.parrot.com/uk\#drones-fpv.

16 http://www.searobotics.com/.

17 Originally considered as social interaction by [98], we believe that "verbal communication" and "acquisition" should be considered separately due to the variety and complexity of city scenarios.
}

sensing, planning, acting) are fully or partly performed by a human;

- medium autonomy includes the range of batch processing, decision support and shared control (with or without robot initiative). Generally speaking, the robot performs its tasks autonomously, and the support of an external agent goes from narrowing the set of tasks, to determining the goals and to monitoring the execution;

- high autonomy includes the highest levels of robot autonomy, e.g. executive control, supervisory control and full autonomy, where sensing, planning and acting are performed by the robot under or without external control.

\subsection{Urban Context}

The second context includes aspects describing the city as a complex system of infrastructures.

City actuators The city actuators are the components involved in a city system, but not necessarily included in its actual implementation [19]. This dimension aims at analyzing which actuators of the city are mostly involved in (or are more benefitting from) a robot-city interaction. We consider the following actuators:

- land the geographical area where robots are operating;

- citizens the people involved, operating or benefitting from a robot-city interaction;

- government the public administration appointed by the citizens, which will benefit from the interaction e.g. improving its services;

- technologies the infrastructure and services enabling the robot-city interaction.

City domains In order to analyze which city components (e.g. water and energy systems, roads and transportation networks etc.) are involved in a robot-city interaction, we categorize these according to a set of city domains, that are well-established in the smart city literature [32]:

- economy activities promoting to the innovation, entrepreneurship, economic growth and productivity to enhance competitiveness;

- people activities promoting the citizens' education, plurality, flexibility, creativity, cosmopolitanism, and participation in public life to enhance the social and human capital;

- governance activities enhancing the citizens' participation, public and social services and transparent governance;

- mobility activities to improve the management systems for urban traffic, local and international accessibility, and safety to enhance the transports infrastructure; 
- environment activities to improve energy efficiency, sustainable resource management and environmental protection to protect natural resources;

- living activities to enhance the citizens' quality of life through cultural facilities, health conditions, individual safety, housing quality.

\subsection{Information Context}

The third context concerns the description of the type of information that is exchanged between robots and cities when interacting. Since the goal of the study is to analyze how autonomous agents are deployed in cities that rely on modern technologies, we describe such information in terms of data exchanged during a robot-city interaction. Due to the large information needs of robotics systems, we consider here information produced by the robots' internal sensors as well as information produced by external sensors, provided that these are exchanged as part as the city infrastructure. The dimensions here considered are selected based on the four data dimensions typically used in Data Science [12].

Data volume The volume of data refers to its magnitude. This dimension aims at analyzing the quantity of data generated, stored or simply involved during an interaction between robots and cities. We consider:

- megabytes e.g. tables and files;

- gigabytes e.g. transactions;

- terabytes e.g. datasets and records;

- pentabytes e.g. large real-time data collections.

Data variety Variety is referring to the structural heterogeneity of the data. This dimension aims at analyzing the type of data mostly used, namely how diverse is the information exchanged. Such diversity is categorized as:

- unstructured data such as texts, images or audios;

- semi-structured data unstructured data annotated using markup languages (e.g. XML);

- structured data i.e. as tabular data, XML files, JSON streams, or relational databases;

Data velocity The velocity of data refers to the rate at which data is generated, changed, processed and exchanged. We study here if robot-city interaction works mostly use:

- batch communication of data;

- periodic communication of data;

- real-time communication of data.

Data openness In the context of RCI, the openness of data is a crucial aspect and might be preferred to data veracity, which is often used to determine the data trustworthiness.
With this dimension, we are interested in understanding the data sharing aspect, i.e. whether knowledge is privately exploited or rather (fully or partly) shared. We analyze the RCI scenarios based on two possible values:

- restricted if they only make use of privately accessible data;

- open if they include some available external information such as openly accessible data.

\subsection{Interaction Context}

The last context concerns those aspects which describe the interaction between robots and the single components of a city, namely the land, the citizens, the government and the technologies.

Robot-citizens interaction Here, we aim at describing how the robots interact with the citizens. For this, we can use Hall's proxemic spaces [37], which allow us to identify the interpersonal distance at which such interactions happen. Each space is then combined with the operations that can be performed in that space, as proposed by [47]:

- intimate space (0 to $0.45 \mathrm{~m}$ ca.) the closest space to the self. Allowed actions span from approaching to touching.

- personal space (0.45 to $1.2 \mathrm{~m}$ ca.) generally reserved for interactions with friends and family. Allowed actions include following, approaching and touching.

- social space (1.2 to $3.7 \mathrm{~m} \mathrm{ca}$.) for interactions among acquaintances. Allowed actions include passing, following and approaching.

- public space (from $3.7 \mathrm{~m}$ ): for public speaking interactions. Allowed actions range from none (robot and citizens not interacting at all), to avoiding and following.

Robot-land interaction We look into analyzing which is the type of physical spaces in which a robot-city interaction happens. We consider two basic types of spaces as defined by [34], namely frontstage (open to the public) and backstage spaces (closed to the public). The first ones are then additionally sub-divided based on the type of activities that can be performed, resulting in the following classification:

- exhibit spaces frontstage places that are created to be looked at and passed through without altering them (e.g. public squares);

- passage spaces frontstage places designed for the movement and passage from a space to another (e.g. streets or pathways);

- special use spaces frontstage places reserved for a particular activity (e.g. restaurants, smoking areas); 
- secure spaces public and controlled areas, such as a hospital, a school, an airport;

- backstages private spaces that only allowed people with a key/pass/password can access (e.g. a house).

Robot-government interaction This dimension aims at analyzing the level of engagement of the city administration, e.g. if robots are deployed to demonstrate good city governance, if they cooperate with the city public services through data exchange/task allocation, etc. We consider here:

- yes if robots are appointed by the government or its services, or are contributing to improving them;

- no in the opposite case.

Robot-data interaction This dimension aims at analyzing how robots deal with data from the city, which actions they can perform, how and if they can manage the heterogeneity of datasets, etc. Common patterns on the activities that can be performed on data in a urban context can be found in the literature $[18,96]$ :

- data acquisition all the activities for collecting, checking the quality, filtering and describing new data.

- data processing activities to process, manipulate and analyze the collected data, with the aim of generating new information supporting some data-related tasks;

- data dissemination activities targeted to disseminate, deliver and share the processed information to external systems and end-users.

Robot-robot interaction This dimension describes the interaction that robots can have with other robots. In particular, we aim at exploring at which level the robot-city interactions involve team cooperation (if any), defined by [114] as:

- heterogeneous team if a team is composed by different types of robots;

- homogeneous team if a team involves the same type of robots;

- single-robot team if only one robot is considered (therefore there is no robot-robot interaction).

Given the described framework, the following section summarizes the selected literature according to each presented dimension.

\section{Literature Synthesis}

In this section, we summarize the selected works to provide an initial state-of-the art in the area of Robot-City Interaction and to identify the current gaps of the area. After providing a synthesis based on the four contexts defined in Sect. 3, we give some conclusions based on the RCI areas that were identified during the process. As previously mentioned, all generated data (selected papers and dimensions identified for each of them) can be examined in Table 3 of Appendix at the end of this work.

\subsection{Synthesis by Context}

The RCI dimensions are discussed in this Section from the perspective of the four analytical contexts (i.e. the agent, urban, information and interaction context).

\subsubsection{Agent Context}

In terms of the type of robots employed in RCI works, Fig. 2 shows that wheeled or humanoid robots are mostly involved.

Wheeled non-humanoid platforms are more common, as these are often built ad-hoc, hence cheaper and more customizable; as for humanoid/legged platforms, these tend to be more specific to group-robot interaction scenar-

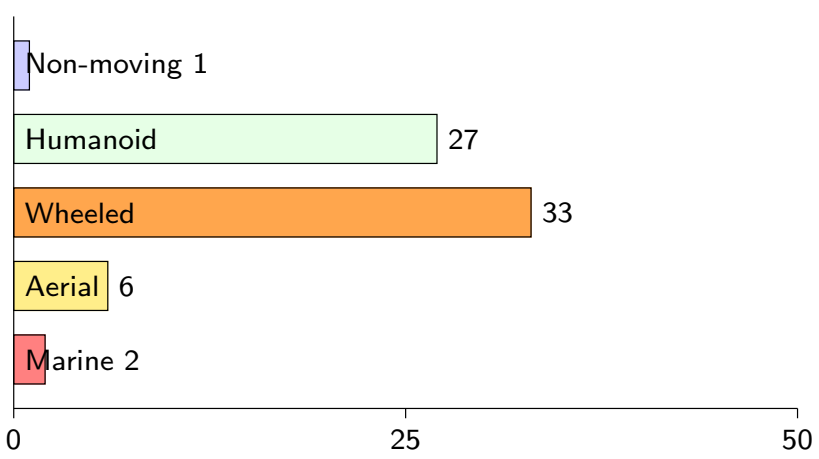

Fig. 2 Most common types of robots in RCI

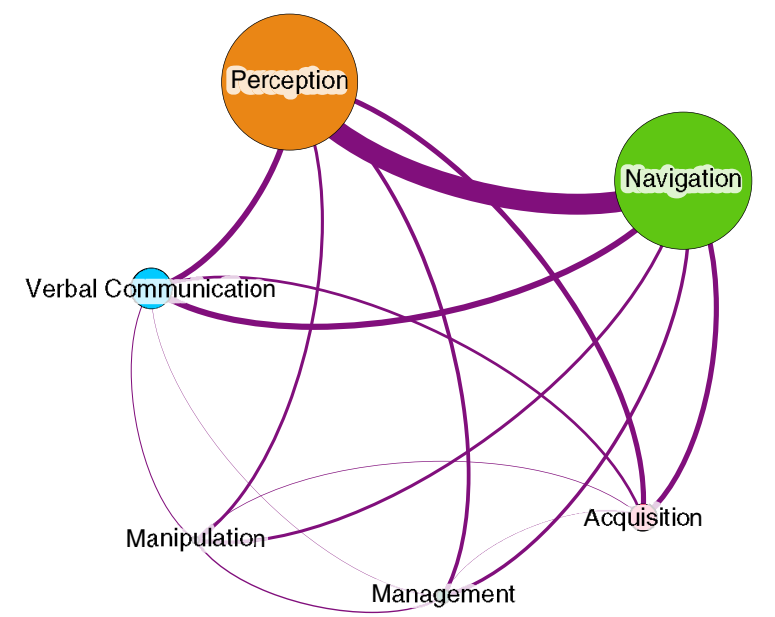

Fig. 3 Robot actions (the nodes) and how frequently they co-occur (the edges) 
ios $[30,33,55,64]$. This is likely due to the presence of the citizens, which might naturally be more inclined to share the urban space with human-friendly presences. Aerial platforms-employed both as single units $[16,26,28,76]$ and in combination with other platforms [60], are less common, likely due to the rather recent emergence of drones as reliable platforms, as well as to the regulations currently restricting their usage in public spaces.

The ability of robots to perform different actions is analyzed in Fig. 3 using the network partitioning technique, which allows to analyze the importance of categories in pairs (i.e. how often they occur together). In the specific, robot actions are represented as nodes varying in size depending on their frequency, while the size of the edges indicates a robot's ability to perform two actions (i.e. the source and target of the edge)-for example, a robot that can perceive and navigate.

Along with the current research trends, navigation and perception are shown to be prominent in RCI, too. The strong co-occurrence between them mostly derives from the fact that perception is naturally required to navigate, which is a fundamental requirement for most of the applications. Indeed, many of the selected works focus on advanced navigation algorithms combined with state-of-the-art sensor technologies $[29,38,56,57,62,90]$. Verbal communication and acquisition, which are medium-sized in the figure, are also somewhat common: This happens mostly in contexts where robots are required to interact with the citizens to achieve their goals, as in $[30,39,45,53,69,87]$. The ability of management is mostly employed in combination with perception and navigation - typically scenarios involving more than one robot, e.g. such as monitoring spaces for security or traffic management purposes [5,40,51,60,61,110,112].

Figure 4 shows the robot autonomy level in the analyzed works. While a rather equal distribution can be observed, the literature reveals that the level of autonomy very much depends on the application domain. Robots with medium to high-level autonomy are mostly required in outdoor sce-

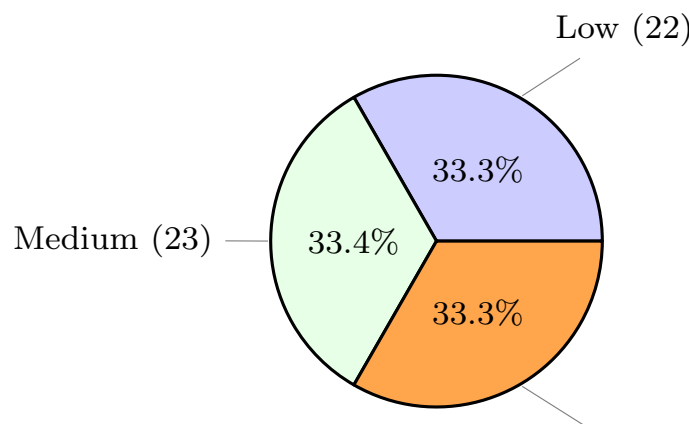

High (22)

Fig. 4 Autonomy of robots in RCI scenarios. Values of this category are exclusive narios where the human presence is not necessary, such as driverless cars $[3,25,40,51,61,110,112]$ and infrastructure maintenance $[17,41,59,67,76,86,89]$; on the contrary, a low to medium level of autonomy is observed when citizens are involved, both through public engagement $[13,22,30,49,53$, $87,88,109]$ and personal assistance $[10,39,45,69,83]$.

\subsubsection{Urban Context}

We summarize here the urban dimensions considered in Sect. 3.2 , i.e. the city actuators and the city domains that mostly take part to the robot-city interactions.

In Fig. 5, we use network partitioning to analyze which city actuators (i.e. components) are mostly involved in a robot-city interaction. Nodes are sized according to how often an actuator was taking part to an interaction-be it a target, promotor or a mean through which the interaction happened; edges are weighted according to how often the two actuators have been observed together. We observe that technologies, intended as the ICT infrastructures employed by a city to better manage its own resources, are largely involved, as demonstrated by their node size and by the strong (thicker) connections they have with government, land and citizens. Interestingly, a large role is also played by the government, showing that many of the scenarios in RCI are intended to improve the services offered by the city. Citizens and land tend to be less involved in RCI, as the weaker connections with the other city actuators demonstrate.

Similarly, Fig. 6 presents the city domains in which robotcity interactions mostly take place. Governance has a central role here, combined with either the people's well-being, the environmental infrastructure or the mobility services. This is also congruent with increasing efforts that governments and municipalities are putting into technological advancements, see initiatives such as the smart cities. As for the domain of living (intended as people's well-being), few records of an interaction are reported. This shows that, despite the advancements of areas such as the Internet of Things, Ambient Intelligence or Ambient Assisted Living, scenarios in which

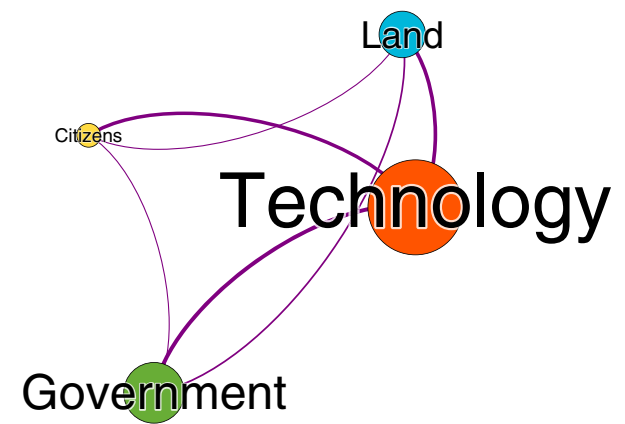

Fig. 5 The actuators of an interaction in RCI scenarios (nodes), and how often two actuators interact (edges) 


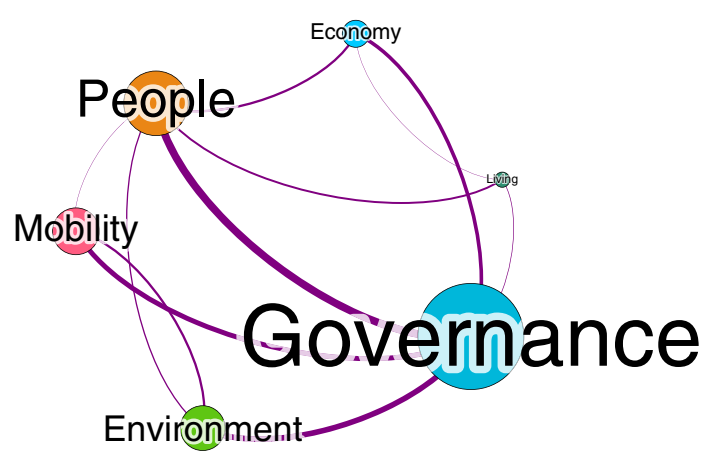

Fig. 6 Domains of a city that are mostly involved in RCI scenarios: a central role is observed for governance

smart homes interact with city administrations seems yet to be realized.

\subsubsection{Information Context}

The dimensions of Sect. 3.3 analyze the nature of the data exchanged in RCI. Note that categories here are not exclusive, and the robots' own sensor data are considered only if exchanged within the city infrastructure.

Figure 7 shows that RCI scenarios involve low quantities of data, mostly MB and GB (indeed, we reported no cases of TB or PB of data exchanged). This represents a considerable difference w.r.t. sensor networks, big data and smart cities scenarios, in which data infrastructures manage tera- and petabyte-sized datasets [54]. With that said, such infrastructures often have difficulties in managing data at high rates [115], while the data exchange in RCI does happen at a fast rate, as demonstrated by the large percentage of systems exchanging data in real-time (cfr. Fig. 8).

Figure 9 shows that unstructured and semi-structured data are exchanged in the majority of RCI scenarios (vs. few cases using structured data, e.g. $[22,40,65,90,110])$. This

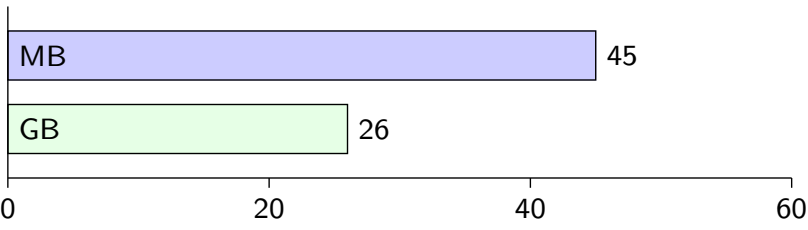

Fig. 7 Volumes of data exchanged in RCI

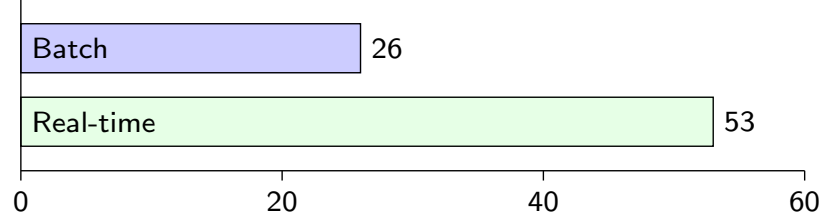

Fig. 8 Velocity at which data are exchanged in RCI

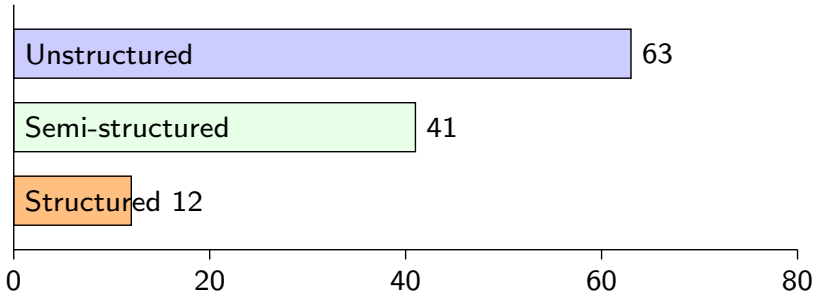

Fig. 9 How diverse are data exchanged in RCI

\begin{tabular}{|llll}
\hline Restricted & & 59 \\
\hline Open7 & & & \\
\hline & & & \\
\hline 0 & 20 & 40 & 60
\end{tabular}

Fig. 10 Usage of open (public) and restricted (private) data in RCI scenarios

reveals that providing a more semantic representation of the data exchanged is still of little emphasis in RCI, as works tend to focus on building ad-hoc cyber-physical systems $[5,10,26,83]$, where robots are often seen as mobile sensors rather than knowledge producers $[60,62,79,81]$. This also conforms with the fact that robotics lacks of established standards and best practices for data representation and exchange, while these have been proven to be fundamental in promoting interoperability in applications involving heterogeneous systems (e.g. the Internet-of-Things [74]).

Finally, Fig. 10 shows that, besides the ongoing efforts of openly sharing knowledge from different sources, very few works in RCI [5,17] have indeed explored the potential of open data to solve their problems.

\subsubsection{Interaction Context}

Here, we aim at understanding how and how much robots interact of the city ecosystem in terms of its single components (i.e. citizens, land, government, technologies).

From the perspective of the relationships between citizens and robots, Fig. 11 reveals that a majority of interactions happen in public spaces, typically in works tackling planning and navigation issues $[3,25,40,41,51,61,86,110,112]$. In this sense, citizens are mostly seen as variables of a highly dynamic environment, which have to be considered equally to other obstacles. With that said, closer interactions of a social or personal nature are also common, namely in scenarios involving citizens for private or public assistance $[10,13,30,49,53,83,87,88,109]$.

Figure 12 show how robots interact with their surrounding geographical space (the land). Expectedly, backstage spaces are less common in RCI scenarios, followed by secure spaces and special spaces such as hospitals $[39,103]$, construction sites $[76,86,89]$ and underground city infrastructures $[48,75]$. 
Publicly available passage and exhibit spaces are overall more common, specifically in outdoor scenarios.

Figure 13 reports that few works have some form of robotgovernment interaction, typically in cases in which robots are employed by the public administration as a support for security or maintenance $[16,26-28,79,81,107]$.

Figure 14 shows that robots mainly acquire and process data from the city, while dissemination (being more timeconsuming) is less common $[16,17,79,81,107]$, and mostly employed when teams of robots are involved.

Finally, Fig. 15 shows how a large amount of RCI works employ robots as single units. This is mostly due to the taskallocation difficulties arising when integrating several robots in a large-scale scenario. Indeed, teams of robots seems to be used in more controlled contexts, such as road navigation, city infrastructure maintenance or city security.

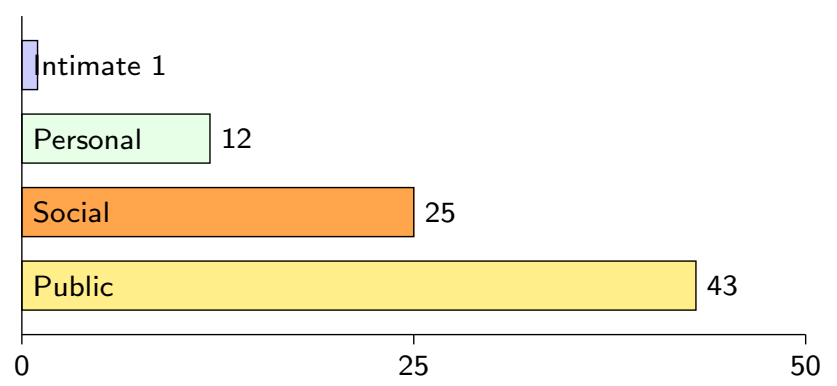

Fig. 11 Types of interaction between robots and citizens

\begin{tabular}{|l|l|}
\hline Exhibit & 32 \\
\hline Passage & 29 \\
\hline Special use & 20 \\
\hline Secure & 13 \\
\hline Backstage 8 & \\
\hline 0 & 25 \\
\hline
\end{tabular}

Fig. 12 Spatial nature of the robot-city interaction in the observed works

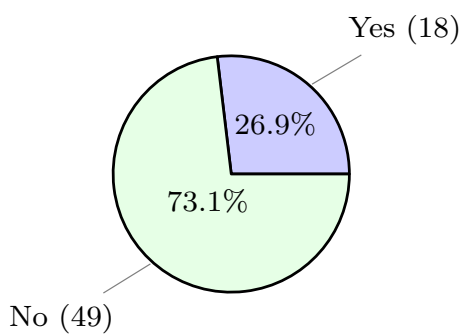

Fig. 13 Interaction between robots and government. Values of this category are exclusive

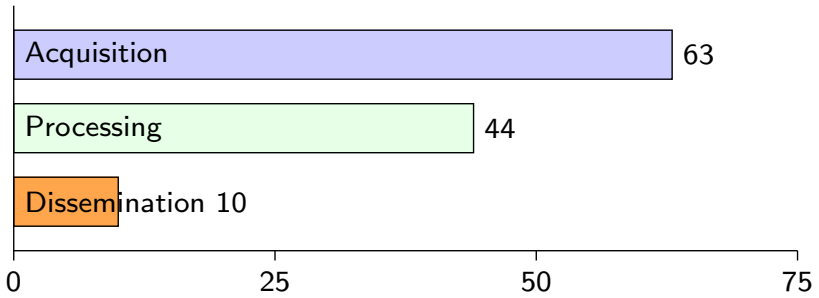

Fig. 14 Actions performed on city data by robots

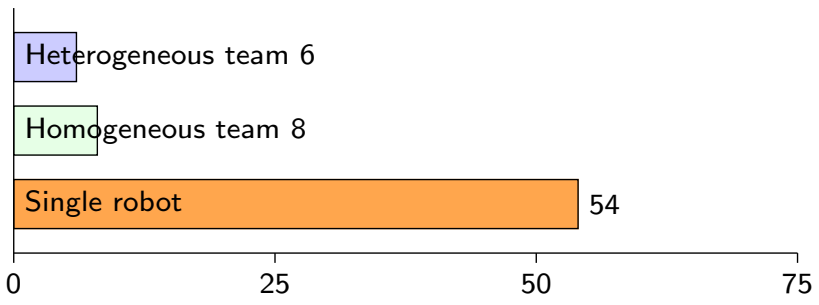

Fig. 15 How robots interact between each other in urban scenarios

\subsection{Synthesis by RCI Area}

One of the main considerations to be drawn from the previous section is that a series of patterns have emerged during the analysis, which allow us to group the reviewed papers according to the aspects and characteristics they share. We grouped the literature in six macro-areas, which we have identified as: Urban Security (US), Citizen Assistance (CA), Public Space Engagement (PSE), Mobility in Urban Dynamic Environments (DE), Autonomous Urban Transportation (AU) and Urban Maintenance (UM). These areas are helpful not only to have a better view over the main RCI themes, but also to understand more precisely specific characteristics and open challenges. We invite the reader to use Figs. 16, 17, 18 and 19 as support and reference for the description of each area. Also, it is worth mentioning here that many works might naturally overlap but, for the sake of simplification, they are presented as belonging to one area only.

\subsubsection{Urban Security}

Urban Security is the area focusing on techniques and methodologies to embed robotics systems into the city's security infrastructures. Examples of urban security applications can be, for instance, urban search\&rescue (USAR), crime prevention, emergency/parking management and monitoring. These require state-of-art sensor technologies (e.g. radars, laser scanners), advanced management of data infrastructures, visual techniques for object detection, and performant algorithms for autonomous navigation, task allocation and planning.

We found in this area works focusing on the collaboration between robots and city services with the aim of supporting the citizens during an emergency [26,44,107], 


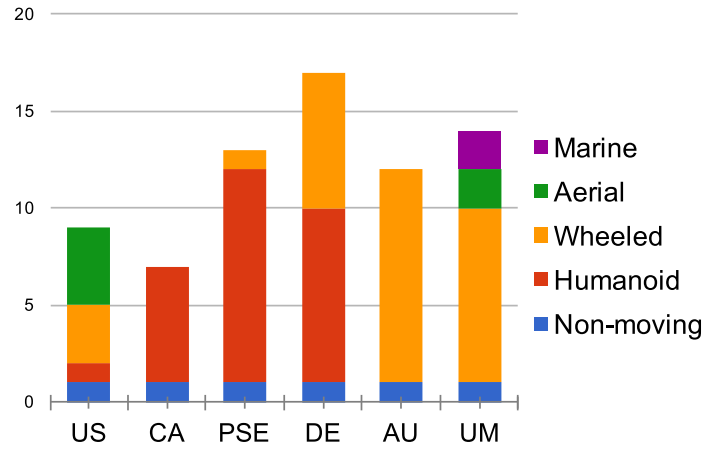

(a) Robot type.

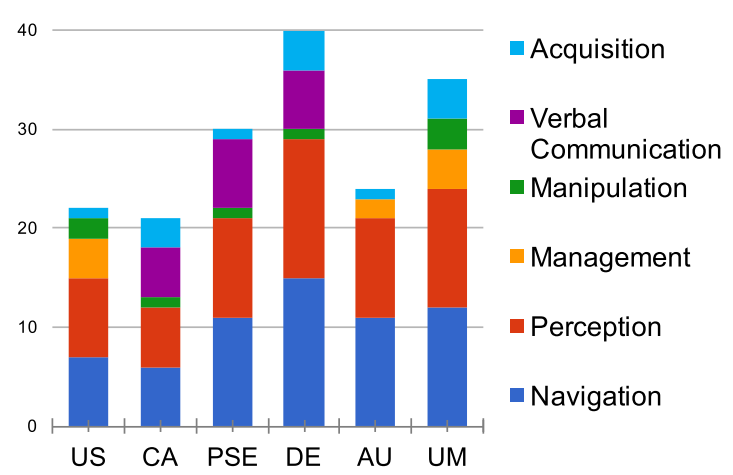

(b) Robot actions.

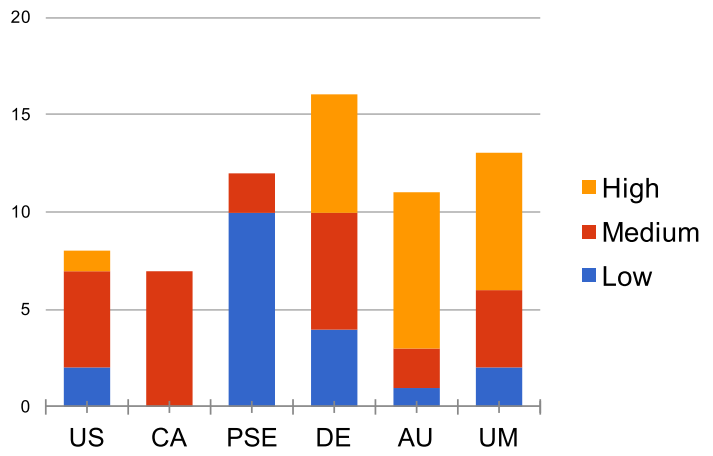

(c) Robot autonomy.

Fig. 16 Agent context organized by RCI area

intelligent designs of networked infrastructures that integrate robots [27,28,78,81], and planning/ decision-making solutions for monitoring situations such as parkings or road networks [16,79].

As reported in Figs. 16, 17, 18 and 19, works in urban security present the following characteristics:

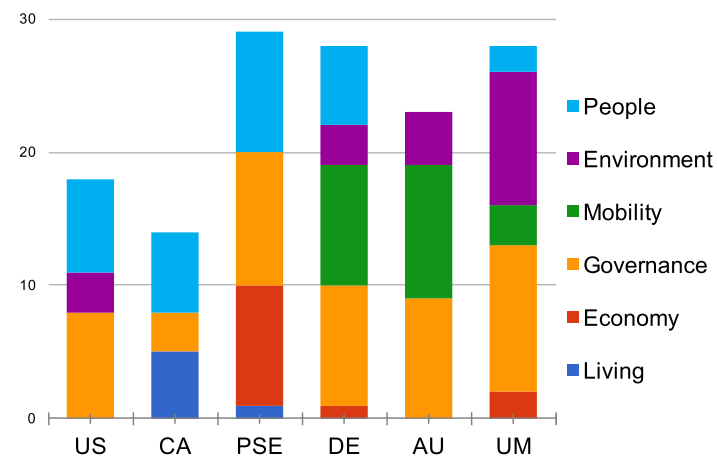

(a) City actuators.
- highly mobile platforms such as UAVs and wheeled robots, which are able to precisely perform outdoor navigation, environmental perception and manage a situation;

- robots operating mostly autonomously, sometimes partially supervised by humans;

- central role of the government as an actor w.r.t. land/ citizens, as well as the governance and the citizens' wellbeing representing the city aspects mostly studied;

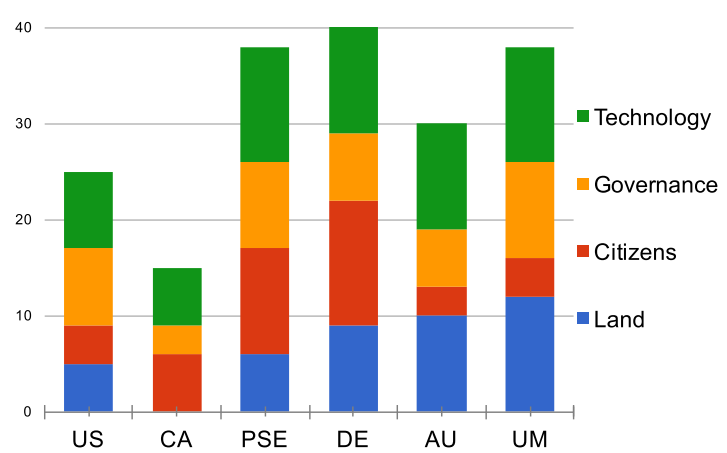

(b) City domains.

Fig. 17 Urban context organized by RCI area 


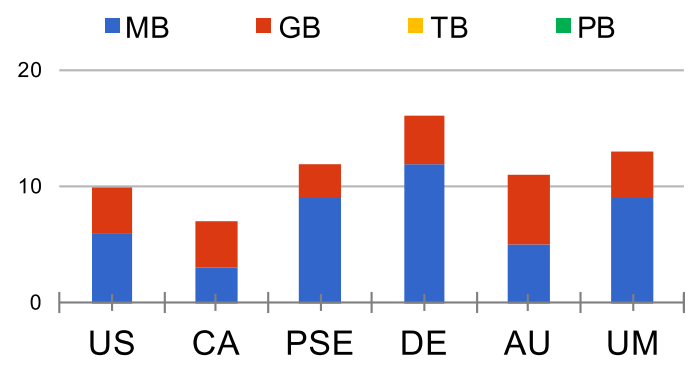

(a) Data volume.

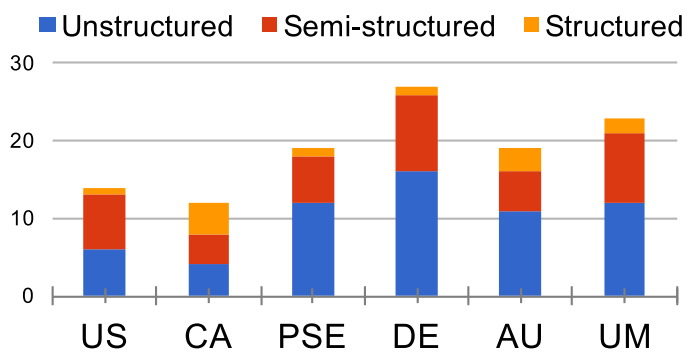

(c) Data variety.

Fig. 18 Information context organized by RCI area

- low quantities of (mostly) raw and semi-structured sensor data communicated;

- communication of data both in batch and periodically, e.g. if an emergency is detected;

- some usage of open data, e.g. OpenStreetMap ${ }^{18}$ in [28];

- personal to public interactions between robots and citizens, generally in public spaces such as exhibit or passage places;

- high cooperation between robots and the city municipality;

- robots able to acquire, process and share knowledge, generally operating in a team rather as a single element.

\subsubsection{Citizen Assistance}

This area comprehends applications of robots employed to carry out public assistive services for the citizens. Methods and technologies from Ambient Assisted Living, sensor networks, Cloud Robotics and HRI are combined in order to present solutions that aim at improving the citizens' quality of life, either in their homes or in spaces providing assistive services (e.g. hospitals).

Works in this area range from intelligent systems and software architectures testing and simulating how robots communicate with intelligent environments [55,103] and perform assistive-specific tasks $[10,83]$, to real-world appli-

${ }^{18}$ https://www.openstreetmap.org.

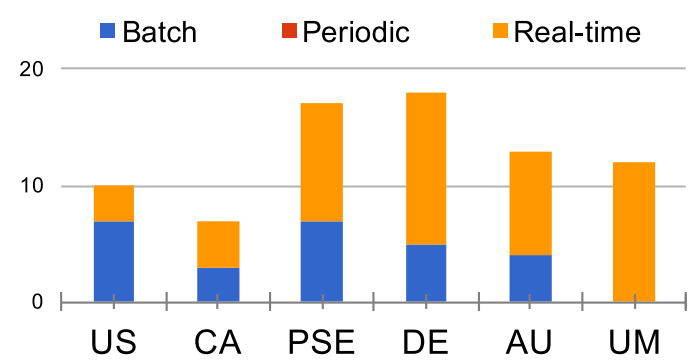

(b) Data velocity.

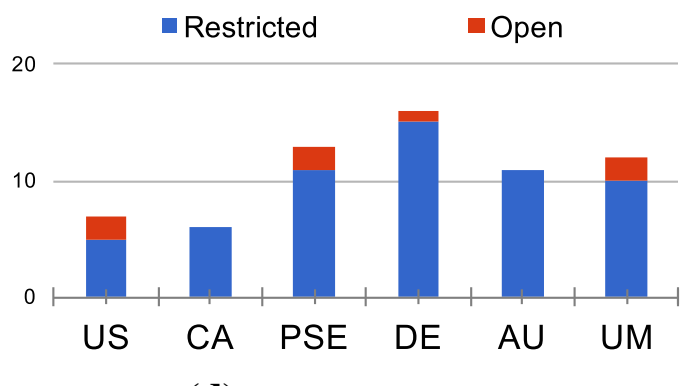

(d) Data openness.

cations where mobile platforms are continuously operating autonomously $[39,45,69]$.

The main characteristics observed in this area are:

- wheeled and humanoid platforms with a medium autonomy, both due to the close contact with the citizens;

- basic capabilities of navigation and perception, essential verbal communication, partial acquisition capabilities aiming at a more personalized interaction with the citizens;

- involvement of the government as an actor, in combination with the citizens and technologies, while the land actuator is of secondary importance;

- focus on the people and living city domains, and lower interest in the economical, environmental and mobility ones;

- exchanged data low in volume (mostly MB), communicated both in batch (when receiving a user input) and real-time (through the perceiving sensors);

- employment of unstructured, semi-structured and structured data, but no usage of open data;

- essentially personal interactions between citizens and a single mobile agent, mainly happening in spaces with restricted access (backstage places such as houses, and secure/special use spaces such as hospitals);

- no robot-government interaction;

- data acquisition and processing capabilities, and little ability to disseminate (and share) data. 


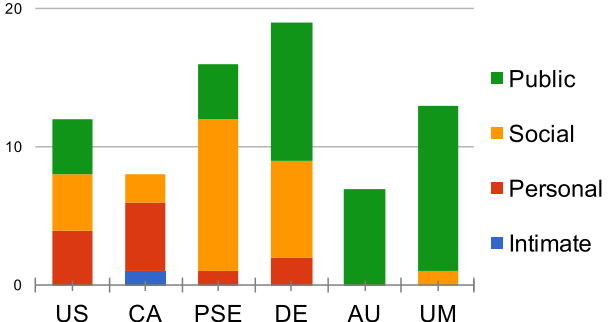

(a) Robot-citizens interaction.

20

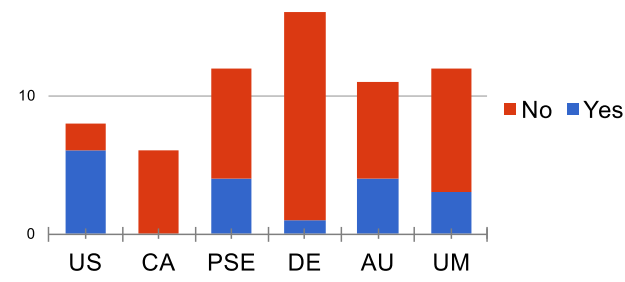

(c) Robot-government interaction.

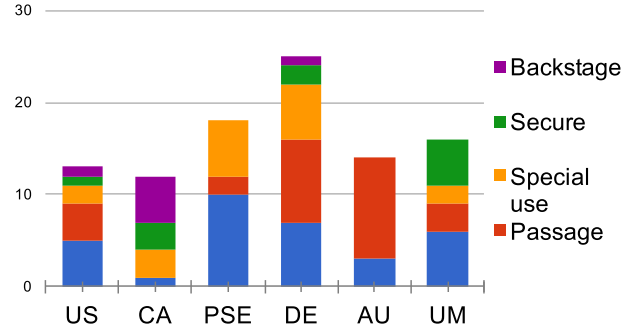

(b) Robot-land interaction.

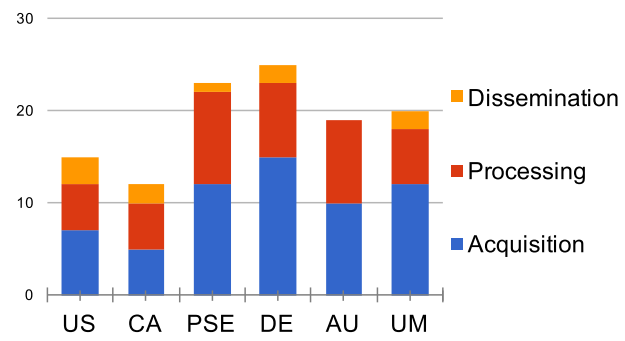

(d) Robot-data interaction.

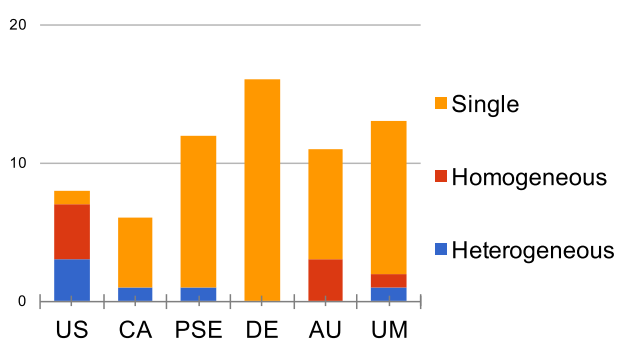

(e) Robot-robot interaction.

Fig. 19 Interaction analysis organized by RCI area

\subsubsection{Public Space Engagement}

Public Space Engagement is the area focusing on employing robots in everyday social environments (for example, public squares, museums and shopping malls) and on studying how robots socially and ethically interact with the citizens. Techniques from ubiquitous computing, wireless sensor networks, HRI and social science are employed to study both a wide range of aspects, from infrastructure and networking, to ethical and social acceptance.

Works here can be divided into architectures and frameworks allowing interaction between robots, humans and ubiquitous sensors $[33,68,94]$, and works aiming at analyzing the public engagement and social acceptance, either on demand [30,53,87,109], or through personalization [22], or directly using the robots' proactivity $[13,49,88]$.

We observe here the following characteristics:

- wheeled and humanoid platforms, where navigation, perception and communication abilities are essential. In some cases, manipulation or acquisition are also supported (as in $[13,88])$;

- a low level of autonomy, due to the employment of robots in much larger, dynamic, and uncertain environments;

- large involvement of citizens, government and technologies in the interactions, and minor importance of the land;

- usage of autonomous agents to support the economical, municipal and well-being aspect of the city;

- low quantities of unstructured/semi-structured data exchanged, both in batch (if the system is queried) or in real-time (sensor data);

- some usage of open data in public contexts, as in [22,30];

- mostly social or public interactions, rare personal interactions;

- interactions happening in front spaces, both exhibit and special use spaces (e.g. public squares and museums);

- no robot-government interaction.

- mostly single robots are employed;

- data acquisition and processing capabilities, less investigation of data dissemination and knowledge sharing. 


\subsubsection{Mobility in Urban Dynamic Environments}

In this area, we find research investigating how robots can interact with urban dynamic environment for pedestrianlike autonomous navigation. A wide range of techniques, spanning from perception, navigation and planning to image processing, are investigated here.

Works in this area focus on robot navigation in highly constrained indoor environments (e.g. a museum or an exhibition) $[11,29,95,99]$ or outdoor areas, both autonomously $[1$, $56,57]$, through interaction with the citizens if the space is unknown $[23,64]$. Other works focus on improving the simultaneous localization and navigation through the integration of some a priori knowledge, e.g. some pre-analyzed human behaviors $[63,70,77,102]$ or knowledge from some external sources $[7,65,80]$.

Observed characteristics here are:

- wheeled platforms (both humanoid and non), equipped with navigation, perception and (less often) verbal communication abilities;

- higher levels of autonomy;

- a larger (w.r.t. the previous areas) involvement of the land and citizens as actuators of the interactions, lower presence of the government;

- mobility and well-being of people being the most concerned city domains;

- low quantities of unstructured/semi-structured data exchanged, mostly in batch;

- little usage of open data (with exception of [11]);

- mainly social and public robot-citizens interactions;

- mostly social or public interactions, happening in exhibit, passage and special use spaces;

- little robot-government interaction (only reported in [63]);

- employment of mostly single robots, which do not necessitate data dissemination, due to the focus on performing advanced navigation.

\subsubsection{Autonomous Urban Transportation}

Autonomous Urban Transportation is the area concerned with using robot agents to monitor, control and manage the traffic and mobility of the city. The works in this area combine techniques for image processing, data collection, navigation and planning, with the aim of improving the performance of intelligent vehicles which can navigate in dynamic and uncertain environments.

We find here both works tackling problems of perception and sensing, e.g. how to navigate in hard conditions such as obstacles, rain, or fog $[38,62,90,113]$, and works tackling problems issuing from coordination and knowledge sharing, including multi-vehicle coordination $[3,40,51,110]$, citizen- vehicle coordination $[25,112]$ or traffic-based coordination [61].

More specific characteristics are as follows:

- highly autonomous wheeled platforms (typically, autonomous car-like), equipped with highly developed perception, navigation and (sometimes, see $[25,40]$ ) management capabilities;

- centrality of the land and technologies actuator, less priority given to both government and citizens;

- large focus on the mobility aspect of the city;

- data exchanged in low quantities, privately and in realtime;

- some efforts put in exchanging structured data [40,90, 110];

- public robot-citizens interactions in passage spaces (roads and crossings);

- occasional robot-government interaction;

- data acquisition and processing are fundamental actions, dissemination of data is yet to be employed;

- mostly teams of the same kind of robots (e.g. vehicles) employed.

\subsubsection{Urban Maintenance}

Urban Maintenance is the area focusing on applying robotics solutions to maintain the city's distributed infrastructures. Enabling techniques in this case come from machine learning, ubiquitous computing, wireless sensor networks and motion planning.

We find in this area works focusing on the data acquisition problem to improve autonomous planning and navigation of outdoor machineries $[17,41,76,86,89]$, works for environmental recognition $[42,48,59,67,75]$ and works aiming at optimizing cooperation and resource consumption $[5,60]$.

This area has the following characteristics:

- heterogeneous platforms types, from non-humanoid wheeled robots to marine/aerial robots;

- essential navigation, perception and management, sometimes paired with the capability of acquiring new information of the surrounding environment $[5,17,59,67]$ or manipulating it $[41,86,89]$;

- high level of autonomy;

- land, government and technologies as core participants of an interaction, less involvement of the citizens;

- governance and environments as the most concerned city domains, few cases considering the people's wellbeing [17] and economical aspects [41,86];

- low quantities of raw and semi-structured data exchanged generally privately and in real-time, few cases of structured or open data $[5,17,89]$;

- mostly public robot-citizens interaction; 


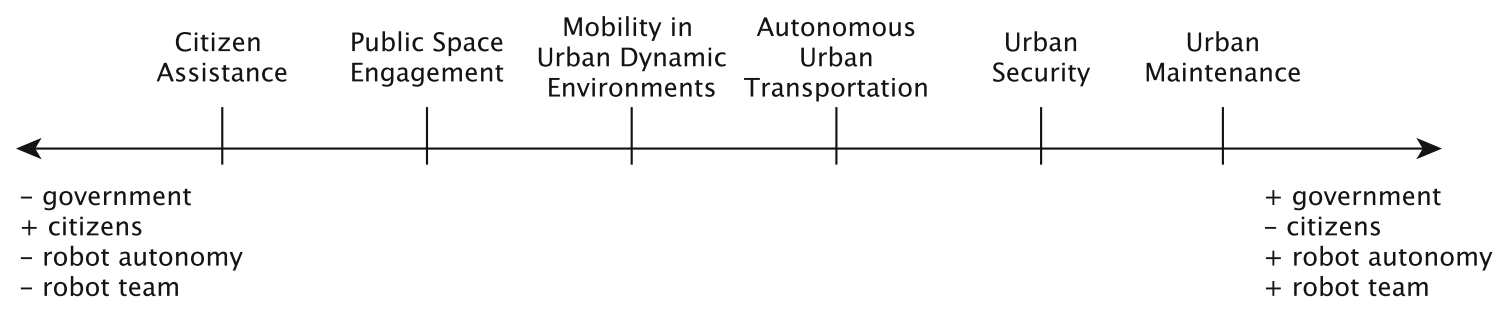

Fig. 20 Research areas of RCI

- robots operating essentially in front spaces, either as single units or homogeneous teams;

- some interactions between robots and government [17, 60];

- acquisition and data processing more employed than data dissemination.

The research areas of RCI here presented are shown in Fig. 20 based on the most evident characteristics, namely how much the government or citizens are involved, and what is the autonomy level of robots in the area and whether they operate mostly as teams of single units. An overall summary of the dimensions can also be seen in Table 2 .

\section{The RCI Research Landscape}

Based on the analysis we conducted, we characterize in this section RCI as a multidisciplinary field, while providing a discussion on its research landscape.

\subsection{Summary}

Here, we look at answering the question: what did we discover from our literature review, and how has our view changed since the beginning our work?

The literature review confirmed our hypothesis that integrating robotics platforms into modern city systems is a complex problem, as induced by the variety of research areas involved. However, the growing interest on research topics involving robots in cities calls for an identification of the open problems under a unified perspective.

From our first analysis (the agent context of Sect. 4.1.1), we learnt how cities are currently integrating robots with advanced perception and navigation capabilities, thanks to the modern motion planning algorithms and sensing technologies. While the autonomy of the agents tends to vary depending on the research area, the type of robots which are mostly employed are ground robots. This is mostly due to three reasons: first, robust off-the-shelf ground robots are nowadays common, while highly performing non-ground robots are still prohibitive in costs, and therefore only employed in controlled scenarios; second, the techniques at the state-of-the-art for ground robot mobility are much more advanced with respect to aerial and marine robots; third, current regulations limit the deployment of aerial robots and therefore experimenting with those in concrete settings is still problematic.

The analysis of the urban context (Sect. 4.1.2) confirmed our idea that the interest in integrating robot technologies in the city's ecosystems is growing, and showed how much the city actors and domains are being involved in the robot-city interactions. Advanced data and communication technologies, which are largely involved in RCI scenarios, allow the creation of solid city infrastructures, guaranteeing efficient robot-city interactions. Public institutions and governments, at the same time, encourage investments and initiatives in this area with the aim of improving their offer and services. The lack of balance in the way city actuators take part in robot-city interactions (e.g. citizens or land having a lower priority), as well as the small number of scenarios involving the economical and people well-being aspects, suggest what new directions can be undertaken in the near future.

Some interesting conclusions about the nature of the information exchanged between robots and city systems can also be drawn from the analysis of the information context in Sect. 4.1.3. Robots in RCI deal with small amounts of realtime, unstructured (sensory) data, which do not impose any model constraints. This constitutes a remarkable discrepancy w.r.t. how information in managed within modern city systems (see, for instance, the smart cities initiatives), where a high degree of organization is required to manage the heterogeneous information (both sensory and common-sense knowledge) gathered from different sources. Similarly, while one of the main aspects of smart cities is the usage of open data to promote knowledge sharing, the surveyed works seem to make mostly usage of proprietary or closed data.

The difficulty of sharing knowledge in RCI scenarios also emerges from the analysis of the interaction dimensions (see Sect. 4.1.4). Indeed, we learnt that robots are extensively used as mobile agents for data acquisition and processing (also) thanks to the cities' advanced network technologies, while less efforts are put in improving the cooperative aspects-as demonstrated by the few literature involving intimate-to- 
Table 2 Summary of the characteristics for each RCI area

\begin{tabular}{|c|c|c|c|c|c|c|}
\hline Dim. Area & $\begin{array}{l}\text { Urban } \\
\text { security }\end{array}$ & $\begin{array}{c}\text { Citizen } \\
\text { assistance }\end{array}$ & $\begin{array}{l}\text { Public space } \\
\text { engagement }\end{array}$ & $\begin{array}{c}\text { Mobility in } \\
\text { Urban dynamic } \\
\text { environments }\end{array}$ & $\begin{array}{c}\text { Autonomous } \\
\text { Urban } \\
\text { transportation }\end{array}$ & $\begin{array}{c}\text { Urban } \\
\text { maintainance }\end{array}$ \\
\hline Robot type & Highly mobile & Humanoid & $\begin{array}{l}\text { Wheeled, } \\
\text { Humanoid }\end{array}$ & $\begin{array}{l}\text { Wheeled, Aerial, } \\
\text { Marine }\end{array}$ & Wheeled & Wheeled \\
\hline $\begin{array}{l}\text { Robot } \\
\text { actions }\end{array}$ & $\begin{array}{l}\text { Perception, } \\
\text { Navigation, } \\
\text { Management }\end{array}$ & $\begin{array}{l}\text { Perception, } \\
\text { Navigation, } \\
\text { Verbal } \\
\text { Communication }\end{array}$ & $\begin{array}{l}\text { Perception, } \\
\text { Navigation, } \\
\text { Verbal } \\
\text { Communication }\end{array}$ & $\begin{array}{l}\text { Perception, } \\
\text { Navigation, } \\
\text { Management }\end{array}$ & $\begin{array}{l}\text { Perception, } \\
\text { Navigation, } \\
\text { Acquisition }\end{array}$ & $\begin{array}{l}\text { Perception, } \\
\text { Navigation }\end{array}$ \\
\hline $\begin{array}{l}\text { Autonomy } \\
\text { level }\end{array}$ & $\begin{array}{l}\text { Medium to } \\
\text { High }\end{array}$ & Medium & Low & $\begin{array}{l}\text { Medium } \\
\text { to High }\end{array}$ & High & High \\
\hline $\begin{array}{l}\text { City } \\
\text { actuators }\end{array}$ & $\begin{array}{l}\text { Government, } \\
\text { Citizen }\end{array}$ & $\begin{array}{l}\text { Government, } \\
\text { Citizen }\end{array}$ & $\begin{array}{l}\text { Government, } \\
\text { Citizen }\end{array}$ & $\begin{array}{l}\text { Land, } \\
\text { Government }\end{array}$ & Land & Land \\
\hline $\begin{array}{l}\text { City } \\
\text { domains }\end{array}$ & $\begin{array}{l}\text { Government, } \\
\text { Living }\end{array}$ & $\begin{array}{l}\text { People, } \\
\text { Living }\end{array}$ & $\begin{array}{l}\text { Economy, } \\
\text { People, } \\
\text { Governance }\end{array}$ & $\begin{array}{l}\text { Mobility, } \\
\text { People }\end{array}$ & $\begin{array}{l}\text { Mobility, } \\
\text { Environment }\end{array}$ & $\begin{array}{l}\text { Governance, } \\
\text { Environment }\end{array}$ \\
\hline Data volume & $\mathrm{MB}, \mathrm{GB}$ & $\mathrm{MB}, \mathrm{GB}$ & $\mathrm{MB}, \mathrm{GB}$ & MB, GB & $\mathrm{MB}, \mathrm{GB}$ & MB, GB \\
\hline $\begin{array}{l}\text { Data } \\
\text { velocity }\end{array}$ & $\begin{array}{l}\text { Batch/ } \\
\text { periodic }\end{array}$ & $\begin{array}{l}\text { Batch/ } \\
\text { real-time }\end{array}$ & $\begin{array}{l}\text { Batch/ } \\
\text { real-time }\end{array}$ & Real-time & Real-time & Real-time \\
\hline $\begin{array}{l}\text { Data } \\
\text { variety }\end{array}$ & $\begin{array}{l}\text { Mostly } \\
\text { un-/semi- }\end{array}$ & $\begin{array}{l}\text { Un-/semi-/ } \\
\text { structured }\end{array}$ & $\begin{array}{l}\text { Mostly } \\
\text { un-/semi- }\end{array}$ & $\begin{array}{l}\text { Mostly } \\
\text { un-/semi- }\end{array}$ & $\begin{array}{l}\text { Few struc- } \\
\text { tured }\end{array}$ & $\begin{array}{l}\text { Mostly } \\
\text { un-/semi- }\end{array}$ \\
\hline $\begin{array}{l}\text { Data } \\
\text { openness }\end{array}$ & $\begin{array}{l}\text { Mostly } \\
\text { restricted }\end{array}$ & $\begin{array}{l}\text { Only } \\
\text { restricted }\end{array}$ & $\begin{array}{l}\text { Some } \\
\text { open }\end{array}$ & $\begin{array}{l}\text { Some } \\
\text { open }\end{array}$ & $\begin{array}{l}\text { Some } \\
\text { open }\end{array}$ & $\begin{array}{l}\text { Mostly } \\
\text { restricted }\end{array}$ \\
\hline $\begin{array}{l}\text { Robot-citizens } \\
\text { interaction }\end{array}$ & $\begin{array}{l}\text { Personal to } \\
\text { public }\end{array}$ & Personal & $\begin{array}{l}\text { Social to } \\
\text { public }\end{array}$ & $\begin{array}{l}\text { Social to } \\
\text { public }\end{array}$ & $\begin{array}{l}\text { Public to } \\
\text { social }\end{array}$ & Public \\
\hline $\begin{array}{l}\text { Robot-land } \\
\text { interaction }\end{array}$ & $\begin{array}{l}\text { Exhibit spaces, } \\
\text { Passage spaces }\end{array}$ & $\begin{array}{l}\text { Backstage spaces, } \\
\text { Exhibit spaces, } \\
\text { Passage spaces }\end{array}$ & $\begin{array}{l}\text { Exhibit spaces, } \\
\text { Special spaces }\end{array}$ & $\begin{array}{l}\text { Front } \\
\text { spaces }\end{array}$ & $\begin{array}{l}\text { Front } \\
\text { spaces }\end{array}$ & $\begin{array}{l}\text { Front } \\
\text { spaces }\end{array}$ \\
\hline $\begin{array}{l}\text { Robot-gov. } \\
\text { interaction }\end{array}$ & High & None & None & Some & None & None \\
\hline $\begin{array}{l}\text { Robot-data } \\
\text { interaction }\end{array}$ & $\begin{array}{l}\text { Acquisition, } \\
\text { Processing, } \\
\text { Dissemination }\end{array}$ & $\begin{array}{l}\text { Acquisition, } \\
\text { Processing }\end{array}$ & $\begin{array}{l}\text { Acquisition, } \\
\text { Processing }\end{array}$ & $\begin{array}{l}\text { Acquisition, } \\
\text { Processing }\end{array}$ & $\begin{array}{l}\text { Acquisition, } \\
\text { Processing }\end{array}$ & $\begin{array}{l}\text { Acquisition, } \\
\text { Processing }\end{array}$ \\
\hline $\begin{array}{l}\text { Robot-robot } \\
\text { interaction }\end{array}$ & $\begin{array}{l}\text { Homo- } \\
\text { Heterogeneous } \\
\text { teams }\end{array}$ & $\begin{array}{l}\text { Single } \\
\text { teams }\end{array}$ & $\begin{array}{l}\text { Single } \\
\text { teams }\end{array}$ & $\begin{array}{l}\text { Mostly single } \\
\text { teams }\end{array}$ & $\begin{array}{l}\text { Mostly single } \\
\text { teams }\end{array}$ & $\begin{array}{l}\text { Single teams, } \\
\text { Homogeneous } \\
\text { teams }\end{array}$ \\
\hline
\end{tabular}

personal robot-citizens interaction, multi-robots cooperation (both heterogeneous and homogeneous teams), robotgovernance interaction, and data sharing/dissemination.

\subsection{Main Characteristics of RCI}

Here, we aim at answering the following question: which are the main characteristics and challenges of the Robot-City Interaction, based on our findings?

First, we saw throughout the analysis how RCI has an interdisciplinary nature, due to the number of different disciplines contributing to it. Based on this, we say that:
Robot-City Interaction is a cross-disciplinary field of study, combining cutting-edge methods and technologies from a wide range of areas such as Robotics, Information and Communication Technologies, Artificial Intelligence, Knowledge Representation, Ethics, Security and Privacy, to design and implement systems in which autonomous agents are integrated in complex urban environments.

Second, the analysis helped in better assessing the characteristics of RCI, featuring aspects specific to both modern cities and highly autonomous robots, namely: 
- urban robots which act autonomously in city contexts, both as data producers and data consumers of the city knowledge;

- smart infrastructures that centralize and digitalize the urban knowledge from a number of heterogeneous sources, e.g. such as power, water, transports and, ultimately, autonomous robots;

- open-ended interactions between robots and the surrounding environment, where proactivity in decisionmaking is necessary to deal with an unforeseeable number of situations to be dealt with;

- assistive services i.e. robots are deployed by and for the city to improve its own services and, consequently, the quality of life of its citizens.

Third, we could then depict the ideal RCI scenario, where:

(i) robots are enabled with the main cognitive abilities, e.g. they are able to fully observe (through sensors and feedbacks), reason (through integration, analysis and decision-making) and act (through collaborative data sharing);

(ii) all the actuators of a city (land, citizens, technologies and governance) are involved, i.e. they should all be playing a role in the scenario and benefit from it;

(iii) a two-way interaction between robot and the city ecosystem happens, in which robots contribute to the city knowledge as mobile data collectors (through data acquisition), but also benefit from the heterogenous knowledge provided by the city (through data dissemination and sharing).

In this view, the main challenge for RCI is to understand how robots can interact with these large-scale dynamic environments in a way that such an interaction respects the three constraints of involving fully autonomous cognitive robots, the whole of the city actuators and a bi-directional data communication. As a consequence, works in RCI should focus on designing, implementing and evaluating methods to enable robots to flexibly act in city contexts, namely through the technological advancement of both robots and infrastructures, and through solutions to exploit the large amount of knowledge available nowadays. Although scenarios like these are yet to be achieved, there is a number of efforts that can be put or are being put towards their realization, that we present in the next section.

\subsection{RCl: A Research Landscape}

Finally, based on our findings and the characteristics of RCI, which directions can be undertaken, so to facilitate the design and implementation of systems in which robots and cities can better interact with each other?
The answer to this question finds its origins in the areas directly contributing to RCI. In the rest of the section, some directions which could shape RCI in the future are presented based on three perspectives: infrastructure and data challenges, aiming at improving the integration of robots in city ecosystems; knowledge-related challenges aiming at improving how robots can reason and get conclusions about their surrounding environment; and ethical and policy challenges aiming at determining new norms and regulations to allow the actual implementation of RCI scenarios.

\subsubsection{Smart Infrastructures}

A major issue arising from the works analyzed is the difficulty in facing the high dynamism, heterogeneity and scale of modern cities. Factors such as monitoring sensors, subject to deterioration, or the presence of citizens, whose actions are unpredictable, bring uncertainty and contradictions, which are difficult to handle even by the most advanced cognitive robots. Planning in uncertain environments is still a challenge for robotics and, for this reason, few projects have been reported as actually being deployed at large-scale (e.g. cities, buildings, streets); an attempt is currently being held within the European Robotics League, aiming at running a number of "robots in smart city challenges" under the ERL in Smart Cities tournaments. ${ }^{19}$ Without a way to allow robots to understand how to interact with the surrounding environment, it is clearly difficult to envision an efficient robot-city interaction.

One way to go is to look at it from an IoT and sensor networks perspective, therefore finding ways to guarantee robust and maintainable infrastructures for a reliable collection, communication and exchange of data. Sensor technologies currently work in small-scaled environments (smart offices, smart homes) but are often not scalable to the cities, as demonstrated by the little effort put in bringing Ambient Intelligence solutions into RCI scenarios. On the other hand, it is evident that a major challenge is on the difficulty of experimenting with such a large, diverse and physically distributed environment like a city. Issues like deployment, testing and simulation of RCI systems are critical to the development of robust research contributions.

In parallel to this, RCI requires efforts towards rethinking robots not as standalone units, but as part of a larger and complex infrastructure. This means not only improving the platforms' computational and connectivity capabilities, but also to design and implement methods and approaches for reliable data communication and processing, hence guaranteeing the seamless integration of robots with dynamic

\footnotetext{
$\overline{19}$ https://www.sciroc.eu.
} 
interconnected environments. While this would naturally empower robots with the ability of managing the large amounts of data they produce for and they are provided by the city (the data quantity problem), an important aspect that needs to be better investigated is for them to better deal with the variety of information sources (the data heterogeneity problem) [20].

This also opens an interesting challenge from an ICT perspective, in terms of the capabilities offered by data infrastructures provided by the cities. Data infrastructures are a crucial element in modern cities, since they provide the adequate support for the interaction of the different city systems, robots included. Within the smart cities initiatives, central data management infrastructures have emerged as innovative solutions to build a common facility to efficiently manage, integrate and re-deliver the heterogeneous data from the urban environment. These "city data hubs" [21] are centralized nodes that control and monitor the heterogeneous information provided by the different city systems (e.g. government services, transport and traffic control, water, health care, energy, waste), and whose aim is to reduce the development costs for the applications relying on such services, as well as enabling intelligent data processing mechanisms (mining, analytics, aggregation, alignment, linking) at the scale of the entire city, in a common data infrastructure.

A robust infrastructure for data communication is the necessary condition for the interaction of robots with city environments, and it would allow them to better model the environment and better plan for goal achievement. In order to do this, such infrastructures require new algorithms to process, compute, secure and privatize the information flow from robots to the city, and new mechanisms that clearly expose how to make sense of the available data. In other words, the Data Science techniques that have been employed so far only in highly restricted scenarios (see the RoboEarth [108] framework), have to be adapted to allow more flexible online data processing and sharing mechanisms. Using data with a high degree of organization, or delegating the computation to the main reasoning engine of the data hubs are solutions which would allow the robots' workload to be relieved, facilitating their management capabilities, their cooperation and their integration in the city infrastructure. By empowering robots with the ability to mine and exploit knowledge from the data hubs, they would be able to filter, prune and restrict their reasoning, therefore improving the performance in achieving their tasks. At the same time, robots should integrate in the city data hubs the knowledge they collected continuously, so that consistent information about objects, people and activities in the environment is always provided to other agents and uncertainty and knowledge gaps are reduced.
In summary, the first research challenge that we can identify is the need of integrating robots in smart city infrastructures, which more specifically requires:

- more robust sensors and network communications to guarantee reliable data exchange;

- increase computation and connectivity capabilities for robots to cope with data volume issues;

- extend and improve the capabilities offered to robots by the city data infrastructures;

- new Data Science solutions to mine and exploit city knowledge and deal with data heterogeneity.

\subsubsection{Knowledge-Based Environments for Robots}

Assuming the symbolic integration between robots and cities, the second direction to take rather concerns the ability of robots to understand and reason with data available from the city. As seen, the lack of structure in the robots' knowledge representations makes the compilation and data processing a time and energy-consuming task. In this view, semantic technologies [8] have an interesting role to play as means to structure knowledge.

Successfully applied in scenarios aggregating knowledge from heterogeneous sources, semantic technologies provide support both to the representation, integration and curation of data across sources, as well as to the interaction between data and domain experts, towards what can be defined as multidomain, browsable and accessible conceptual "knowledge city graphs".

Semantic technologies have proven to have utility in robotics for high-level planning and understanding, and could be exploited as a layer for knowledge representation and exchange in order to facilitate the integration of mobile agents in the cities [101]. Such technologies could hence represent the key that enable robots to behave both as actuators and contributors of a city knowledge base, to better understand the surrounding environment, to reason upon multiple heterogeneous knowledge sources and to improve the performance of their tasks. More specifically:

(i) without imposing specific data-model constraints, such technologies can intensively facilitate the robots' highlevel reasoning, but also their interoperability, cooperation, and knowledge sharing;

(ii) thanks to their standards for representing heterogeneous knowledge, semantic technologies could help in better representing the many types of information required for successfully accomplishing robotics tasks (e.g. exact times, 3D geometric information, kinematic structures and appearance models), whose representation is currently very challenging; 
(iii) in the same way, semantic technologies could also support robots in dealing with the diversity of cognitive abilities and of types of knowledge (hybrid reasoning) that is needed to perform their tasks;

(iv) their flexibility facilitates the representation dynamic environments subject to unexpected and frequent changes, therefore allowing robots to act with more awareness in uncertain and unfamiliar environments.

A further opportunity developed by knowledge-based data management is the use of external knowledge to improve the achievement of robotic tasks. The last decade has seen a huge amount of domain-specific knowledge being openly published in the form structured data, with the objective of encouraging information sharing, reuse and discovery. With this phenomenon of data deluge, building intelligent systems that are able to explore, integrate, and exploit large amounts of heterogeneous data gathered from a variety of distributed sources has become a priority [20,72,100]. Our survey revealed that there is still a long way to go before the machine-readable and accessible knowledge available for reuse and redistribution is exploited by autonomous agents to their full extent. External knowledge could support robots in improving their tasks: for example, a more robust navigation could be performed by relying on open sources representing the geometry of the environment; object search and recognition could be improved through integrating the domain knowledge available in existing ontologies into the robots' semantic maps; while a better understanding of the environment could be achieved if also relying on domain ontologies, rather than relying only on ad-hoc designed robot knowledge representations.

From an AI perspective, more effort has to be put in representing knowledge which is relevant to robotics. There is an urgent need for designing and developing symbolic representations for robots to be more robust and reliable, and efforts focused on representing more common domain knowledge are required (as opposed to the widely-spread instance-based knowledge representations), as this is highly relevant for robots to achieve their tasks. Methods for the evaluation and validation robot knowledge bases are also required. From the institutional perspective, this also means extending and encouraging open data initiatives, through engaging citizens and data providers towards the integration and acceptance of robots acting in smart city environments.

We can define the second research challenge for RCI as the need of empowering robots with the ability of reasoning with the knowledge from the city, addressing problems such as:

- leveraging semantic technologies to increase interoperability between robots and city ecosystems;
- exploiting the large amounts of machine-accessible external (and open) knowledge to improve robot tasks;

- enlarging, extending and refining the representations of domain knowledge that can be relevant to robots (and robotics in general);

- encouraging and exploiting open data initiatives.

\subsubsection{Ethical Regulations and Policies}

The last point of the previous section also relates to the third direction that we have identified in the RCI landscapenamely, how to regulate a robot-city interaction.

Our survey has revealed that several societal and ethical barriers exist, which prevent robots to be extensively employed in cities (see flying drones mostly being used in secure spaces, or driverless systems only used as driving assistants or pedestrian pods). Research areas such as robot ethics, social science, data security and privacy have therefore the opportunity to investigate which methods would allow robots to be more ethically, socially and legally acceptable. HRI approaches are needed to study how to establish fruitful robot-citizens interactions at an intimate and personal distance. When coming to social and public distances, trust issues are to be addressed, as robots in RCI need to operate in environments with citizens that might not have consented to the interaction with them. Social acceptance of robots by naive users is a key issue, and ethical methodologies are needed to guarantee the safety of non-experts creating dynamisms in the environments where robots act, therefore improving the willingness of citizens to share the urban space with robotics platforms. AI trust and transparency tools to explain the logics of robotic behavior and decisionmaking are also needed [106]. Clear regulations and policies establishing the transparency of data exchange and communication are needed, in order for robots to be respectful of the fundamental laws and rights. By improving policy contexts and by focusing on the citizens' needs, public entities and local authorities could in fact understand what robotics technologies can be offered in response to their urban needs, therefore facilitating the interaction of robotics technologies with political and institutional components.

The last research challenge for the RCI is to establish more robot-aware societal regulations, i.e.:

- increase of the robots' social acceptability;

- transparency tools enabling robots to explain their behavior;

- safety dispositions for the citizens when robots operating nearby;

- data protection policies when communicating and exchanging data. 
Based on the discussion above, we can conclude that RCI must combine knowledge-based urban environments with modern data infrastructure technologies and robot-aware regulations.

\subsection{Relation of $\mathrm{RCI}$ to Other Fields}

We acknowledge that Robot-City Interaction stands at the crossing of many fields, from robotics and autonomous and intelligent systems to knowledge and information management. We conclude by presenting how RCI relates and differs to its closely related areas.

Ambient Intelligence Ambient Intelligence is mainly concerned with the application of advanced technologies in private spaces [15]. Although many results from Ambient Intelligence can be inherited by RCI, the latter considers private spaces a part of a larger city system, and highlights therefore how the intelligence of urban structures can contribute to use cases of wider scope, e.g. from buildings to towns [2,14].

Urban Robotics Urban Robotics has been defined as robotics in the service of cities and citizens [85]. While this is very pertinent to RCI, Urban Robotics research applications focus only on exploiting robots to address societal challenges, while omitting the interaction and infrastructure aspects between robots and cities-namely, how these two components can benefit from each other.

Human-Robot Interaction As opposed to Urban Robotics, the main focus of HRI is the interaction between humans and robots (and the ethical and psychological implications of it). HRI studies the different forms of interaction, depending on factors such as the proximity of the participants or the type of robots engaged. RCI and HRI have commonalities, e.g. a solid body a work in HRI finds application in urban spaces, while the proxemics studies help RCI to assess how robots are perceived and received by citizens. The main difference lies in the fact that RCI studies how city services and the citizens' quality of life can be improved by deploying robots as part of an interconnected digital infrastructure.

Roboethics Roboethics also deals with the interaction between robots and humans, but rather focuses on the the human ethical implications of designer, manufacturers, and users of robots [104]. This area overlaps with RCI in what they both address social and ethical issues of the application of robots to our daily lives. Roboethics however focuses on more bio-ethical issues, while RCI addresses ethical implications from a Urban Policy perspective: in other words, in order for robots to operate in a smart city ecosystem, governance measures have to be undertaken too.

Networked Robotics, Cloud Robotics Networked Robotics focuses on the challenges inherent the physical constraints (limited computing and storage capabilities) onboard groups of robot devices connected via wired or wireless com- munication [46]. Cloud Robotics was then promoted to enable networked robotics with cloud computing technologies. Cooperating robots are expected to operate intensively in a city environment, hence these areas can certainly contribute to RCI with a number of solutions and protocols using existing networks not only for decision making, but also for fast knowledge and data sharing. However, Networked Robotics and Cloud Robotics are rather focused on the hardware, networks and scalability aspects with respect to RCI.

\section{Conclusions}

Motivated by the advancements of modern technologies in city systems, here we have presented a first attempt to characterize the field of Robot-City Interaction, its key themes, gaps, guidelines and challenges, and to provide a perspective on how robots can interact in and with complex city environments. In order to do so, we used a literature review methodology that allowed us to identify a set of key dimensions of Robot-City Interactions and a body of works contributing to this emerging area, which we then analyzed and classified according to the defined dimensions. The literature review not only served as a ground field for the RCI, to be used for further reference and extension, but also helped us in the following aspects:

- define RCI as the cross-disciplinary field of study, which combines cutting-edge methods and technologies from a wide range of areas such as Robotics, Information and Communication Technologies, Artificial Intelligence, Knowledge Representation, Ethics, Security and Privacy, to design and implement systems in which autonomous agents are integrated in complex urban systems;

- identify the main characteristics of RCI, namely the infrastructure aspect (robots as part of a digitalised infrastructure managing the city services), the interaction aspect (robots behaving as data producers and data consumers of the city knowledge) and the city service aspect (robots are deployed by and for the city to improve its own services);

- identify the main challenges for RCI, designed with the goal of establishing an interaction between robots and complex environments, where the constraints of involving (1) fully autonomous cognitive robots, (2) the four city actuators and (3) a bi-directional data communication are respected;

- identify the six RCI areas, consisting in Citizen Assistance, Public Space Engagement, Mobility in Urban Dynamic Environments , Autonomous Urban Transportation, Urban Security and Urban Maintenance, and their own characteristics; 
- outline a vision for future RCI research, emphasising the need for combining knowledge-based urban environments with modern data infrastructures technologies and robot-aware regulations.

Future work can go in several directions. First, we intend to explore several aspects of the RCI landscape-namely, the use of semantic technologies as a knowledge representation layer and the creation of robot-city scenarios at a reduced-scale. Second, we envision to further refine the RCI framework, by providing more detailed analyses of techniques, technical issues (environments, time and costs), impact and key insights specific to each RCI and to single framework dimensions (e.g. robots autonomy or the robotgovernment interaction). Finally, we intend to include a temporal aspect in the survey, through analyzing how RCI and the different dimensions evolved in time.

\section{Compliance with Ethical Standards}

Conflict of interest The authors declare that they have no conflict of interest.

Open Access This article is distributed under the terms of the Creative Commons Attribution 4.0 International License (http://creativecomm ons.org/licenses/by/4.0/), which permits unrestricted use, distribution, and reproduction in any medium, provided you give appropriate credit to the original author(s) and the source, provide a link to the Creative Commons license, and indicate if changes were made.

\section{Appendix}

See Table 3. 
Table 3 Overview of the literature analysis

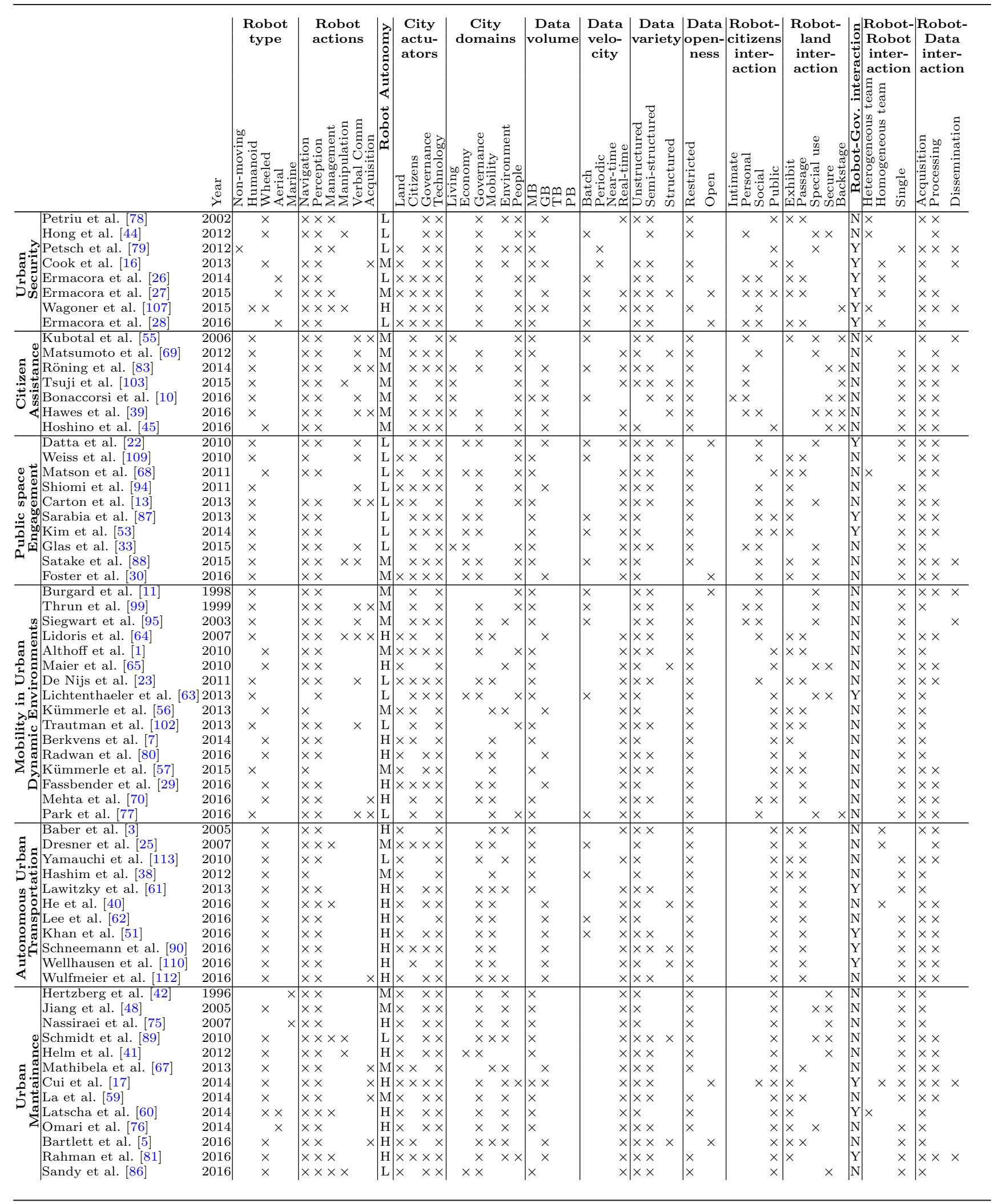




\section{References}

1. Althoff D, Althoff M, Wollherr D, Buss M (2010) Probabilistic collision state checker for crowded environments. In: 2010 IEEE international conference on robotics and automation (ICRA). IEEE, pp 1492-1498

2. Azhar S (2011) Building information modeling (bim): trends, benefits, risks, and challenges for the aec industry. Leaders Manag Eng 11(3):241-252

3. Baber J, Kolodko J, Noel T, Parent M, Vlacic L (2005) Cooperative autonomous driving: intelligent vehicles sharing city roads. IEEE Robot Autom Mag 12(1):44-49

4. Bakıcı T, Almirall E, Wareham J (2013) A smart city initiative: the case of barcelona. J Knowl Econ 4(2):135-148

5. Bartlett O, Gurau C, Marchegiani L, Posner I (2016) Enabling intelligent energy management for robots using publicly available maps. In: 2016 IEEE/RSJ international conference on intelligent robots and systems (IROS). IEEE, pp 2224-2229

6. Beer J, Fisk AD, Rogers WA (2014) Toward a framework for levels of robot autonomy in human-robot interaction. J Hum Robot Interact 3(2):74

7. Berkvens R, Jacobson A, Milford M, Peremans H, Weyn M (2014) Biologically inspired slam using wi-fi. In: 2014 IEEE/RSJ international conference on intelligent robots and systems (IROS 2014). IEEE, pp 1804-1811

8. Berners-Lee T, Hendler J, Lassila $\mathrm{O}$ et al (2001) The semantic web. Sci Am 284(5):28-37

9. Bischof S, Karapantelakis A, Nechifor C-S, Sheth AP, Mileo A, Barnaghi P (2014) Semantic modelling of smart city data. https:// corescholar.libraries.wright.edu/knoesis/572

10. Bonaccorsi M, Fiorini L, Cavallo F, Saffiotti A, Dario P (2016) A cloud robotics solution to improve social assistive robots for active and healthy aging. Int J Soc Robot 8(3):393-408

11. Burgard W, Cremers AB, Fox D, Hähnel D, Lakemeyer G, Schulz D, Steiner W, Thrun S (1998) The interactive museum tour-guide robot. In: Aaai/iaai, pp 11-18

12. Cao L (2017) Data science: challenges and directions. Commun ACM 60(8):59-68

13. Carton D, Turnwald A, Wollherr D, Buss M (2013) Proactively approaching pedestrians with an autonomous mobile robot in urban environments. In: Desai J, Dudek G, Khatib O, Kumar V (eds) Experimental robotics. Springer tracts in advanced robotics, vol 88. Springer, Heidelberg, pp 199-214

14. Cavallo F, Limosani R, Manzi A, Bonaccorsi M, Esposito R, Di Rocco M, Pecora F, Teti G, Saffiotti A, Dario P (2014) Development of a socially believable multi-robot solution from town to home. Cognit Comput 6(4):954-967

15. Cook DJ, Augusto JC, Jakkula VR (2009) Ambient intelligence: technologies, applications, and opportunities. Pervasive Mob Comput 5(4):277-298

16. Cook K, Bryan E, Yu H, Bai H, Seppi K, Beard R (2013) Intelligent cooperative control for urban tracking with unmanned air vehicles. In: 2013 international conference on unmanned aircraft systems (ICUAS). IEEE, pp 1-7

17. Cui Y, Voyles RM, Lane JT, Mahoor MH (2014) Refresh: a selfadaptation framework to support fault tolerance in field mobile robots. In: 2014 IEEE/RSJ international conference on intelligent robots and systems (IROS 2014). IEEE, pp 1576-1582

18. Daga E, d'Aquin M, Adamou A, Motta E (2016) Addressing exploitability of smart city data. In: 2016 IEEE international smart cities conference (ISC2). IEEE, pp 1-6

19. Dameri RP (2013) Searching for smart city definition: a comprehensive proposal. Int J Comput Technol 11(5):2544-2551

20. d'Aquin M, Motta E (2016) The epistemology of intelligent semantic web systems. Synth Lect Semant Web Theory Technol $6(1): 1-88$
21. d'Aquin M, Davies J, Motta E (2015) Smart cities' data: challenges and opportunities for semantic technologies. IEEE Internet Comput 19(6):66-70

22. Datta C, Vijay R (2010) Neel: an intelligent shopping guide using web data for rich interactions. In: 2010 5th ACM/IEEE international conference on human-robot interaction (HRI). IEEE, pp $87-88$

23. De Nijs R, Juliá M, Mitsou N, Gonsior B, Wollherr D, Kühnlenz K, Buss M (2011) Following route graphs in urban environments. In: 2011 IEEE RO-MAN. IEEE, pp 363-368

24. Del Casino VJ Jr (2016) Social geographies ii: robots. Prog Hum Geogr 40(6):846-855

25. Dresner KM, Stone P (2007) Sharing the road: autonomous vehicles meet human drivers. IJCAI 7:1263-1268

26. Ermacora G, Toma A, Rosa S, Bona B, Chiaberge M, Silvagni M, Gaspardone M, Antonini R (2014) A cloud based service for management and planning of autonomous uav missions in smart city scenarios. In: International workshop on modelling and simulation for autonomous systems. Springer, pp 20-26

27. Ermacora G, Rosa S, Bona B (2015) Sliding autonomy in cloud robotics services for smart city applications. In: Proceedings of the 10th annual ACM/IEEE international conference on humanrobot interaction extended abstracts. ACM, pp 155-156

28. Ermacora G, Toma A, Antonini R, Rosa S (2016) Leveraging open data for supporting a cloud robotics service in a smart city environment. In: Menegatti E, Michael N, Berns K, Yamaguchi H (eds) Intelligent autonomous systems 13. Advances in intelligent systems and computing, vol 302. Springer, Cham, pp 527-538

29. Fassbender D, Heinrich BC, Wuensche H-J (2016) Motion planning for autonomous vehicles in highly constrained urban environments. In: 2016 IEEE/RSJ international conference on intelligent robots and systems (IROS). IEEE, pp 4708-4713

30. Foster ME, Alami R, Gestranius O, Lemon O, Niemelä M, Odobez J-M, Pandey AK (2016) The mummer project: engaging humanrobot interaction in real-world public spaces. In: International conference on social robotics. Springer, pp 753-763

31. Fund U.N.P. (2007) Unleashing the potential of urban growth. http://www.unfpa.org/sites/default/files/pub-pdf/695_filename_ sowp2007_eng.pdf. Accessed July 2017

32. Giffinger R, Pichler-Milanović N (2007) Smart cities: ranking of European medium-sized cities. Centre of Regional Science, Vienna University of Technology, Wien

33. Glas DF, Kamei K, Kanda T, Miyashita T, Hagita N (2015) Human-robot interaction in public and smart spaces. In: Mohammed S, Moreno JC, Kong K, Amirat Y (eds) Intelligent assistive robots. Springer, Berlin, pp 235-273

34. Goffman E et al (1978) The presentation of self in everyday life. Harmondsworth, London

35. Goodrich MA, Schultz AC (2007) Human-robot interaction: a survey. Found Trends Hum Comput Interact 1(3):203-275

36. Gottdiener M, Budd L, Lehtovuori P (2015) Key concepts in urban studies. Sage, Thousand Oaks

37. Hall ET (1966) The hidden dimension. Doubleday \& Co, New York

38. Hashim MSM, Lu T-F, Basri HH (2012) Dynamic obstacle avoidance approach for car-like robots in dynamic environments. In: 2012 IEEE symposium on computer applications and industrial electronics (ISCAIE), pp 130-135

39. Hawes N, Burbridge C, Jovan F, Kunze L, Lacerda B, Mudrová L, Young J, Wyatt JL, Hebesberger D, Körtner T, Ambrus R, Bore N, Folkesson J, Jensfelt P, Beyer L, Hermans A, Leibe B, Aldoma A, Faulhammer T, Zillich M, Vincze M, Al-Omari M, Chinellato E, Duckworth P, Gatsoulis Y, Hogg DC, Cohn AG, Dondrup C, Fentanes JP, Krajník T, Santos JM, Duckett T, Hanheide M (2016) The STRANDS project: long-term autonomy in everyday environments. CoRR, abs/1604.04384. arXiv:1604.04384 
40. He M, Takeuchi E, Ninomiya Y, Kato S (2016) Precise and efficient model-based vehicle tracking method using raoblackwellized and scaling series particle filters. In: 2016 IEEE/RSJ international conference on intelligent robots and systems (IROS). IEEE, pp 117-124

41. Helm V, Ercan S, Gramazio F, Kohler M (2012) Mobile robotic fabrication on construction sites: Dimrob. In: 2012 IEEE/RSJ international conference on intelligent robots and systems (IROS). IEEE, pp 4335-4341

42. Hertzberg J, Kirchner F (1996) Landmark-based autonomous navigation in sewerage pipes. In: Proceedings of the 1st Euromicro workshop on advanced mobile robot. IEEE, pp 68-73

43. Hollands RG (2008) Will the real smart city please stand up? intelligent, progressive or entrepreneurial? City 12(3):303-320

44. Hong JH, Min B-C, Taylor JM, Raskin V, Matson ET (2012) Nl-based communication with firefighting robots. In: 2012 IEEE international conference on systems, man, and cybernetics (SMC). IEEE, pp 1461-1466

45. Hoshino S, Ugajin S (2016) Adaptive patrolling by mobile robot for changing visitor trends. In: 2016 IEEE/RSJ international conference on intelligent robots and systems (IROS). IEEE, pp 104-110

46. Hu G, Tay WP, Wen Y (2012) Cloud robotics: architecture, challenges and applications. IEEE Netw 26(3):21-28

47. Hüttenrauch H, Eklundh KS, Green A, Topp EA (2006) Investigating spatial relationships in human-robot interaction. In: 2006 IEEE/RSJ international conference on intelligent robots and systems. IEEE, pp 5052-5059

48. Jiang B, Sample AP, Wistort RM, Mamishev AV (2005) Autonomous robotic monitoring of underground cable systems. In: 12th international conference on advanced robotics. ICAR' 05 . Proceedings. IEEE, pp 673-679

49. Kanda T, Shiomi M, Miyashita Z, Ishiguro H, Hagita N (2010) A communication robot in a shopping mall. IEEE Trans Robot 26(5):897-913

50. Kasap ÇB (2016) Philosophy of interaction. Current Topics in Social Sciences, p 97

51. Khan MM, Ali H, Berns K, Muhammad A (2016) Road traversability analysis using network properties of roadmaps. In: 2016 IEEE/RSJ international conference on intelligent robots and systems (IROS). IEEE, pp 2960-2965

52. Khorov E, Lyakhov A, Krotov A, Guschin A (2015) A survey on ieee 802.11 ah: an enabling networking technology for smart cities. Comput Commun 58:53-69

53. Kim RH, Moon Y, Choi JJ, Kwak SS (2014) The effect of robot appearance types on motivating donation. In: Proceedings of the 2014 ACM/IEEE international conference on human-robot interaction. ACM, pp 210-211

54. Kitchin R (2014) The real-time city? big data and smart urbanism. GeoJournal 79(1):1-14

55. Kubotal N, Shimomura Y (2006) Human-friendly networked partner robots toward sophisticated services for a community. In: SICE-ICASE. International joint conference. IEEE, pp 48614866

56. Kümmerle R, Ruhnke M, Steder B, Stachniss C, Burgard W (2013) A navigation system for robots operating in crowded urban environments. In: 2013 IEEE international conference on robotics and automation (ICRA). IEEE, pp 3225-3232

57. Kümmerle R, Ruhnke M, Steder B, Stachniss C, Burgard W (2015) Autonomous robot navigation in highly populated pedestrian zones. J Field Robot 32(4):565-589

58. Kuper A (2013) The social science encyclopedia. Routledge, Abingdon

59. La HM, Gucunski N, Kee S-H, Yi J, Senlet T, Nguyen L (2014) Autonomous robotic system for bridge deck data collection and analysis. In: 2014 IEEE/RSJ international conference on intelligent robots and systems (IROS 2014). IEEE, pp 1950-1955

60. Latscha S, Kofron M, Stroffolino A, Davis L, Merritt G, Piccoli M, Yim M (2014). Design of a hybrid exploration robot for air and land deployment (herald) for urban search and rescue applications. In: 2014 IEEE/RSJ international conference on intelligent robots and systems (IROS 2014). IEEE, pp 1868-1873

61. Lawitzky A, Wollherr D, Buss M (2013) Energy optimal control to approach traffic lights. In: 2013 IEEE/RSJ international conference on intelligent robots and systems (IROS). IEEE, pp $4382-4387$

62. Lee U, Jung J, Shin S, Jeong Y, Park K, Shim DH, Kweon I-S (2016) Eurecar turbo: a self-driving car that can handle adverse weather conditions. In: 2016 IEEE/RSJ international conference on intelligent robots and systems (IROS). IEEE, pp 2301-2306

63. Lichtenthäler C, Peters A, Griffiths S, Kirsch A (2013) Social navigation-identifying robot navigation patterns in a path crossing scenario. In: International conference on social robotics. Springer, pp 84-93

64. Lidoris G, Bauer KKA, Xu T, Kuhnlenz K, Wollherr D, Buss M (2007) The autonomous city explorer project: aims and system overview. In: IEEE/RSJ international conference on intelligent robots and systems. IROS 2007. IEEE, pp 560-565

65. Maier D, Kleiner A (2010) Improved gps sensor model for mobile robots in urban terrain. In: 2010 IEEE international conference on robotics and automation (ICRA). IEEE, pp 4385-4390

66. Manyika J, Chui M, Bughin J, Dobbs R, Bisson P, Marrs A (2013) Disruptive technologies: advances that will transform life, business, and the global economy, vol 180. McKinsey Global Institute San Francisco, San Francisco

67. Mathibela B, Posner I, Newman P (2013) A roadwork scene signature based on the opponent colour model. In: 2013 IEEE/RSJ international conference on intelligent robots and systems (IROS). IEEE, pp 4394-4400

68. Matson ET, Min B-C (2011) M2m infrastructure to integrate humans, agents and robots into collectives. In: 2011 IEEE instrumentation and measurement technology conference (I2MTC). IEEE, pp 1-6

69. Matsumoto T, Satake S, Kanda T, Imai M, Hagita N (2012) Do you remember that shop? Computational model of spatial memory for shopping companion robots. In:2012 7th ACM/IEEE international conference on human-robot interaction (HRI). IEEE, pp $447-454$

70. Mehta D, Ferrer G, Olson E (2016) Autonomous navigation in dynamic social environments using multi-policy decision making. In: 2016 IEEE/RSJ international conference on intelligent robots and systems (IROS). IEEE, pp 1190-1197

71. Mori K, Yamashita T (2015) Methodological framework of sustainability assessment in city sustainability index (csi): a concept of constraint and maximisation indicators. Habitat Int 45:10-14

72. Motta E, Sabou M (2006) Next generation semantic web applications. In: Asian semantic web conference. Springer, pp 24-29

73. Mumford L (1937) What is a City? na

74. Murdock P, Bassbouss L, Kraft A, Bauer M, Logvinov O, Ben Alaya M, Longstreth T, Bhowmik R, Martigne P, Brett P, Mladin C, Chakraborty R, Monteil T, Dadas M, Davies J, Nappey P, Diab W, Raggett D, Drira K, Wang C (2016) Semantic interoperability for the web of things. https://hal.archives-ouvertes.fr/hal01362033/

75. Nassiraei AA, Kawamura Y, Ahrary A, Mikuriya Y, Ishii K (2007) Concept and design of a fully autonomous sewer pipe inspection mobile robot kantaro. In: 2007 IEEE international conference on robotics and automation. IEEE, pp 136-143

76. Omari S, Gohl P, Burri M, Achtelik M, Siegwart R (2014) Visual industrial inspection using aerial robots. In: 2014 3rd international 
conference on applied robotics for the power industry (CARPI). IEEE, pp 1-5

77. Park C, Ondřej J, Gilbert M, Freeman K, O'Sullivan C (2016) Hi robot: Human intention-aware robot planning for safe and efficient navigation in crowds. In: 2016 IEEE/RSJ international conference on intelligent robots and systems (IROS). IEEE, pp 3320-3326

78. Petriu EM, Patry GG, Whalen TE, Al-Dhaher A, Groza VZ (2002) Intelligent robotic sensor agents for environment monitoring. In: 2002 IEEE international symposium on virtual and intelligent measurement systems VIMS'02. IEEE, pp 14-19

79. Petsch K, Dotzlaf P, Daubenspeck C, Duthie N, Mock A (2012) Automated parking space locator: Rsm. In: ASSE North central section conference

80. Radwan N, Tipaldi GD, Spinello L, Burgard W (2016) Do you see the bakery? Leveraging geo-referenced texts for global localization in public maps. In: 2016 IEEE international conference on robotics and automation (ICRA). IEEE, pp 4837-4842

81. Rahman A, Jin J, Cricenti A, Rahman A, Palaniswami M, Luo $\mathrm{T}$ (2016) Cloud-enhanced robotic system for smart city crowd control. J Sens Actuator Netw 5(4):20

82. Rajan K, Saffiotti A (2017) Towards a science of integrated AI and robotics. Artif Intell 247:1-9

83. Röning J, Holappa J, Kellokumpu V, Tikanmäki A, Pietikäinen M (2014) Minotaurus: a system for affective human-robot interaction in smart environments. Cognit Comput 6(4):940-953

84. Russell S, Norvig P, Intelligence A (1995) A modern approach. Artif Intell 25:27

85. Salvini P (2017) Urban robotics: towards responsible innovations for our cities. Robot Auton Syst (2017). https://doi.org/10.1016/j.robot.2017.03.007. ISSN 0921$8890 . \quad \mathrm{http}: / / \mathrm{www}$. sciencedirect.com/science/article/pii/ S0921889016303505

86. Sandy T, Giftthaler M, Dörfler K, Kohler M, Buchli J (2016) Autonomous repositioning and localization of an in situ fabricator. In: 2016 IEEE international conference on robotics and automation (ICRA). IEEE, pp 2852-2858

87. Sarabia M, Le Mau T, Soh H, Naruse S, Poon C, Liao Z, Tan KC, Lai ZJ, Demiris Y (2013) icharibot: design and field trials of a fundraising robot. In: International conference on social robotics. Springer, pp 412-421

88. Satake S, Hayashi K, Nakatani K, Kanda T (2015) Field trial of an information-providing robot in a shopping mall. In: 2015 IEEE/RSJ international conference on intelligent robots and systems (IROS). IEEE, pp 1832-1839

89. Schmidt D, Proetzsch M, Berns K (2010) Simulation and control of an autonomous bucket excavator for landscaping tasks. In: 2010 IEEE international conference on robotics and automation (ICRA). IEEE, pp 5108-5113

90. Schneemann F, Heinemann P (2016) Context-based detection of pedestrian crossing intention for autonomous driving in urban environments. In: 2016 IEEE/RSJ international conference on intelligent robots and systems (IROS). IEEE, pp 2243-2248

91. Scholtz J (2003) Theory and evaluation of human robot interactions. In: Proceedings of the 36th annual Hawaii international conference on system sciences. IEEE, p 10

92. Scollon R, Scollon SW (2003) Discourses in place: language in the material world. Routledge, Abingdon

93. Sheridan TB, Verplank WL (1978) Human and computer control of undersea teleoperators. Technical report, DTIC Document

94. Shiomi M, Sakamoto D, Kanda T, Ishi CT, Ishiguro H, Hagita N (2011) Field trial of a networked robot at a train station. Int J Soc Robot 3(1):27-40

95. Siegwart R, Arras KO, Bouabdallah S, Burnier D, Froidevaux G, Greppin X, Jensen B, Lorotte A, Mayor L, Meisser M et al (2003) Robox at expo. 02: a large-scale installation of personal robots. Robot Auton Syst 42(3):203-222
96. Sinaeepourfard A, Garcia J, Masip-Bruin X, Marin-Tordera E, Yin X, Wang C (2016) A data lifecycle model for smart cities. In: 2016 international conference on information and communication technology convergence (ICTC). IEEE, pp 400-405

97. SPARC (2013) Strategic research agenda for robotics in 2014 2020. https://www.eu-robotics.net/cms/upload/topic_groups/ SRA2020_SPARC.pdf. Accessed Sept 2018

98. Steinfeld A, Fong T, Kaber D, Lewis M, Scholtz J, Schultz A, Goodrich M (2006) Common metrics for human-robot interaction. In: Proceedings of the 1st ACM SIGCHI/SIGART conference on human-robot interaction. ACM, pp 33-40

99. Thrun S, Bennewitz M, Burgard W, Cremers AB, Dellaert F, Fox D, Hahnel D, Rosenberg C, Roy N, Schulte J, et al (1999) Minerva: a second-generation museum tour-guide robot. In: 1999 IEEE international conference on robotics and automation. Proceedings, vol 3. IEEE

100. Tiddi I (2016) Explaining data patterns using knowledge from the web of data. Ph.D. thesis, The Open University

101. Tiddi I, Bastianelli E, Bardaro G, d'Aquin M, Motta E (2017) An ontology-based approach to improve the accessibility of rosbased robotic systems. In: Proceedings of the knowledge capture conference (K-CAP2017). ACM, p 13

102. Trautman P, Ma J, Murray RM, Krause A (2013) Robot navigation in dense human crowds: the case for cooperation. In: 2013 IEEE international conference on robotics and automation (ICRA). IEEE, pp 2153-2160

103. Tsuji T, Mozos OM, Chae H, Pyo Y, Kusaka K, Hasegawa T, Morooka K, Kurazume R (2015) An informationally structured room for robotic assistance. Sensors 15(4):9438-9465

104. Veruggio G, Operto F (2006) Roboethics: a bottom-up interdisciplinary discourse in the field of applied ethics in robotics. Int Rev Inf Ethics 6(12):2-8

105. Vom Brocke J, Simons A, Niehaves B, Riemer K, Plattfaut R, Cleven A et al (2009) Reconstructing the giant: on the importance of rigour in documenting the literature search process. ECIS 9:2206-2217

106. Wachter S, Mittelstadt B, Floridi L (2017) Transparent, explainable, and accountable ai for robotics. Sci Robot 2(6):eaan6080

107. Wagoner A, Jagadish A, Matson ET, EunSeop L, Nah Y, Tae KK, Lee DH, Joeng J-E (2015) Humanoid robots rescuing humans and extinguishing fires for cooperative fire security system using harms. In: 2015 6th international conference on automation, robotics and applications (ICARA). IEEE, pp 411-415

108. Waibel M, Beetz M, Civera J, d'Andrea R, Elfring J, GalvezLopez D, Häussermann K, Janssen R, Montiel J, Perzylo A et al (2011) Roboearth. IEEE Robot Autom Mag 18(2):69-82

109. Weiss A, Igelsböck J, Tscheligi M, Bauer A, Kühnlenz K, Wollherr D, Buss M (2010) Robots asking for directions: the willingness of passers-by to support robots. In: Proceedings of the 5th ACM/IEEE international conference on human-robot interaction. IEEE Press, pp 23-30

110. Wellhausen L, Jacob MG (2016) Map-optimized probabilistic traffic rule evaluation. In: 2016 IEEE/RSJ international conference on intelligent robots and systems (IROS). IEEE, pp 3012-3017

111. Wirth L (1938) Urbanism as a way of life. Am J Sociol 44(1):1-24

112. Wulfmeier M, Wang DZ, Posner I (2016) Watch this: Scalable cost-function learning for path planning in urban environments. In: 2016 IEEE/RSJ international conference on intelligent robots and systems (IROS). IEEE, pp 2089-2095

113. Yamauchi B (2010) All-weather perception for man-portable robots using ultra-wideband radar. In: 2010 IEEE international conference on robotics and automation (ICRA). IEEE, pp 36103615 
114. Yanco HA, Drury J (2004) Classifying human-robot interaction: an updated taxonomy. In: 2004 IEEE international conference on systems, man and cybernetics, vol 3. IEEE, pp 2841-2846

115. Zicari RV (2014) Big data: challenges and opportunities. Big Data Comput 564

Publisher's Note Springer Nature remains neutral with regard to jurisdictional claims in published maps and institutional affiliations.

Dr. Ilaria Tiddi is a Research Associate at Knowledge Representation and Reasoning group of the the Vrije Universiteit Amsterdam. She was previously Research Associate at the Knowledge Media Institute of the Open University in the UK, where she also obtained her $\mathrm{PhD}$. Her research focuses on the creation of transparent, explainable systems in e-Science and robotics scenarios through a combination of machine learning, semantic technologies, open data and cognitive theories. https://kmitd.github.io/ilaria/.

Dr. Emanuele Bastianelli is a Research Associate at the Interaction $\mathrm{Lab}$ of the Heriot-Watt University, Edinburgh, UK. He got his PhD in Computer Science from the University of Rome Tor Vergata. He previously worked as a Research Associate at the Knowledge Media Institute of the Open University, and as a Research Assistant at the Cognitive Cooperating Robots Lab (Lab Ro.Co.Co.) of Sapienza University of Rome. His research mostly focuses on Machine Learning applied to Natural Language Processing, with a specific target on Language Understanding for robotic applications and conversational AI. During his career, he covered also other areas such as Information Retrieval and Urban Data Mining. https://www.hw.ac.uk/staff/uk/ macs/Emanuele-Bastianelli.htm.
Dr Enrico Daga has a strong technical background being involved in the development of large data management systems since 2008, first at the Italian National Research Council and then with the Knowledge Media Institute of The Open University. His research area is Knowledge Graphs and their applications, with a focus on the traceability of reuse through intelligent processing of metadata applied to licences, policies, and privacy. Current domains of interest are Smart Cities and the Humanities. http://kmi.open.ac.uk/people/member/enrico-daga.

Prof. Mathieu d'Aquin is a Professor of Informatics specialised in data analytics and semantic technologies at the Insight Centre for Data Analytics of the National University of Ireland Galway. He was previously Senior Research Fellow at the Knowledge Media Institute of the Open University, where he led the Data Science Group. His research focuses on sharing and exploiting distributed information using Semantic Web/Linked Data technologies, in domains including medicine, education, smart cities and the Internet of Things. http:// mdaquin.net/.

Prof. Enrico Motta has a Ph.D. in Artificial Intelligence from The Open University, where is currently a Professor in Knowledge Technologies and Head of the Intelligent Systems and Data Science research group. His work spans a variety of aspects at the intersection of big data, semantic and language technologies, intelligent systems, and humancomputer interaction. In particular much of his current work focuses on developing innovative approaches that integrate large-scale data mining with semantic and language technologies, to assist users in making sense of large-scale data and support decision-making in complex scenarios. Application domains include scholarly analytics, smart cities, and digital humanities. http://people.kmi.open.ac.uk/motta/. 